Review

\title{
New development in $\mathrm{Fe} / \mathrm{Co}$ catalysts: Structure modulation and performance optimization for syngas conversion
}

\author{
Yinwen Li, Xin Zhang*, Min Wei \# \\ State Key Laboratory of Chemical Resource Engineering, Beijing Advanced Innovation Center for Soft Matter Science and Engineering, Beijing University \\ of Chemical Technology, Beijing 100029, China
}

\section{A R T I C L E I N F O}

\section{Article history:}

Received 10 April 2018

Accepted 7 May 2018

Published 5 August 2018

\section{Keywords:}

Syngas conversion

Fe/Co catalyst

Structure modulation

Performance optimization

Product selectivity

\begin{abstract}
A B S T R A C T
C1 chemistry is the essence of coal chemistry and natural gas chemistry. Catalytic methods to efficiently convert C1 molecules into fuels and chemicals have been extensively studied. Syngas (CO + $\mathrm{H}_{2}$ ) conversion is the most important industrial reaction system in C1 chemistry, and Fe and Co catalysts, two major industrial catalysts, have been the focus of fundamental research and industrial application. In the last decade, considerable research efforts have been devoted to discoveries concerning catalyst structure and increasing market demands for olefins and oxygenates. Since the development of efficient catalysts would strongly benefit from catalyst design and the establishment of a new reaction system, this review comprehensively overviews syngas conversion in three main reactions, highlights the advances recently made and the challenges that remain open, and will stimulate future research activities. The first part of the review summarizes the breakthroughs in Fischer-Tropsch synthesis regarding the optimization of activity and stability, determination of the active phase, and mechanistic studies. The second part overviews the modulation of catalytic structure and product selectivity for Fischer-Tropsch to olefins (FTO). Catalysts designed to produce higher alcohols, as well as to tune product selectivity in C1 chemistry, are described in the third section. Finally, present challenges in syngas conversion are proposed, and the solutions and prospects are discussed from the viewpoint of fundamental research and practical application. This review summarizes the latest advances in the design, preparation, and application of Fe/Co-based catalysts toward syngas conversion and presents the challenges and future directions in producing value-added fuels.
\end{abstract}

(C) 2018, Dalian Institute of Chemical Physics, Chinese Academy of Sciences. Published by Elsevier B.V. All rights reserved.

\section{Introduction}

C1 chemistry, normally defined as the reactions of reactant molecules containing only one carbon atom, has attracted considerable interest because of its broad range of applications. In the early stages of $\mathrm{C} 1$ chemistry, this term mainly meant syngas $\left(\mathrm{CO}+\mathrm{H}_{2}\right)$ conversion, whose history has already exceeded about 100 years [1-3]. Nowadays, developing clean energy in some countries and regions requires high-efficiency cleaning processes to improve energy consumption and develop abundant coal resources. Syngas conversion, the most important procedure in coal indirect liquefaction technology, has been already developed for diverse reaction systems to produce chemicals with rather high additional value: traditional Fisch-

\footnotetext{
* Corresponding author. Tel: +86-10-64446598; E-mail: zhangxin@mail.buct.edu.cn

\# Corresponding author. Tel: +86-10-64412131; Fax: +86-10-64425385; E-mail: weimin@mail.buct.edu.cn

This work was supported by the National Key Research and Development Program (2017YFA0206804), the National Natural Science Foundation of China (91741104), and the Fundamental Research Funds for the Central Universities (buctylkxj01).

DOI: 10.1016/S1872-2067(18)63100-6 | http://www.sciencedirect.com/science/journal/18722067 | Chin. J. Catal., Vol. 39, No. 8, August 2018
} 
er-Tropsch synthesis (FTS) for diesel and gasoline, increasingly industrialized FTS for unsaturated hydrocarbons (olefins and aromatics), and syngas conversion to higher alcohols [4-12].

Fe and Co catalysts, two types of industrial and commercial catalysts, are the bright stars of fundamental research in syngas conversion. With various target products, the structures of the catalysts must be extensively tuned and modified, despite the similar chemical compositions. The choice of support $[4,13]$, modification of promoters $[14,15]$ and modulation of activation conditions $[16,17]$ can be used to change the size and dispersion of the active phases, change the electron density of active sites, and even induce the formation of new active species. These changes can promote the activation of reactants, weaken the adsorption of products, and increase the selectivity for the desired product. Moreover, the optimization of reaction conditions (temperature and pressure) [18], the transformation of reaction medium [19], and coupling with other reactions [20] allows excellent catalytic performance to be achieved. Accordingly, both direct modification of catalyst structure and indirect optimization of reaction conditions improve catalyst performance.

This article is organized into three parts. The first section will focus on the methodology and techniques applied to conventional Fe/Co catalysts toward increasing the oil yield in FTS. Then, we will overview the breakthroughs in the Fischer-Tropsch to unsaturated hydrocarbons process, especially concerning the design of the catalyst and understanding of the structure-performance relationship. Finally, we will summarize the preparation and characterization of different types of Fe/Co catalysts, as well as the impact of novel promoters and supports, for the syngas to higher alcohols process. The Fe/Co catalysts are a successful example of structure design, preparation, and structure-performance correlation in syngas conversion and provide clues for new developments in heterogeneous catalysis in $\mathrm{C} 1$ chemistry.

\section{Syngas conversion to saturated hydrocarbons}

FTS is a process to convert syngas $\left(\mathrm{CO}+\mathrm{H}_{2}\right)$ to liquid fuels. Among all the catalysts for industrial FTS processes, iron- and cobalt-based catalysts are two major categories whose active phases are, correspondingly, iron carbides and metallic cobalt. Traditionally, Fe-based catalysts are commonly considered to

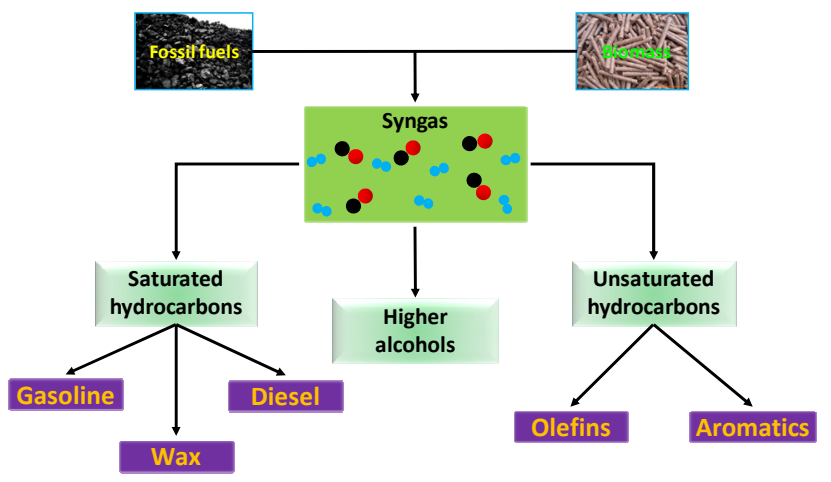

Fig. 1. Three main routes for direct syngas conversion. be catalysts of gasoline; in contrast, Co-based catalysts mainly produce diesel and wax. Because of energy demand and product diversity, several new methodologies and techniques have been used to improve catalyst selectivity. Moreover, breakthroughs in understanding the reaction mechanism have also been made.

\subsection{Recognition of active phase}

Although iron carbides are considered as the active phase, iron carbides are normally a mixture of various iron carbide phases, and it would be desirable to synthesize a single phase to verify its catalytic activity for FTS [1]. Yang et al. [2] synthesized Hägg iron carbide $\left(\mathrm{Fe}_{5} \mathrm{C}_{2}\right)$ nanoparticles by a facile wet chemical route, in which bromide was found to be the key inducing agent for the conversion of $\mathrm{Fe}(\mathrm{CO})_{5}$ to $\mathrm{Fe}_{5} \mathrm{C}_{2}$ in the synthetic process. The as-synthesized $\mathrm{Fe}_{5} \mathrm{C}_{2}$ nanoparticles exhibited intrinsic catalytic activity in FTS (CO conversion: 20\%, $\mathrm{C}_{5+}$ selectivity: $\sim 40 \%$ ). Compared with a conventional reduced hematite catalyst, the $\mathrm{Fe}_{5} \mathrm{C}_{2}$ nanoparticles showed enhanced catalytic performance, demonstrating that $\mathrm{Fe}_{5} \mathrm{C}_{2}$ is the active phase for FTS (Fig. 2). To visualize the structural evolution of the iron nanoparticles involved in the formation and growth of iron carbide nuclei directly, Liu et al. [21] used environmental transmission electron microscopy (TEM) under reaction conditions mimicking FTS; this allowed the formation of the iron carbide nuclei and surface reconstruction of the iron nanoparticle to be identified. Electron diffraction patterns and electron energy-loss spectra provided a detailed picture from initial activation to final degradation of iron under synthesis gas, and high-resolution (HR)-TEM images allowed the identification of carbide and oxide intermediates.

$\mathrm{Fe}_{2.2} \mathrm{C}$ is considered as an active phase that possesses higher activity than that of $\mathrm{Fe}_{5} \mathrm{C}_{2}$. Chun et al. [16] activated the precipitated iron-based catalysts with syngas with different amounts of $\mathrm{CO}_{2}(0 \%, 20 \%, 33 \%$, and $50 \%)$. $\mathrm{CO}_{2}$-containing syngas improved the performance of active iron carbides induced by an increased ratio of $\mathrm{Fe}_{2.2} \mathrm{C}$ to $\mathrm{Fe}_{5} \mathrm{C}_{2}$ and a decreased fraction of inactive bulk carbons, as shown by X-ray diffraction (XRD), Mössbauer spectroscopy (MES), and temperature-programmed hydrogenation (TPH) measurements. The sample reduced in syngas with $50 \% \mathrm{CO}_{2}$ showed the best performance that the productivity of $\mathrm{C}_{19+}$ hydrocarbons at $50 \% \mathrm{CO}_{2}\left(0.160 \mathrm{~g} \mathrm{~g}_{\text {(cat) }}{ }^{-1}\right.$ $\mathrm{h}^{-1}$ ) was about twice higher than the value at $0 \% \mathrm{CO}_{2}(0.0797 \mathrm{~g}$ $\mathrm{g}_{\text {(cat) }}{ }^{-1} \mathrm{~h}^{-1}$ ).

\subsection{Optimization of the catalyst}

Although the process of FTS has been industrialized for almost one hundred years, performance enhancement remains a popular topic of investigation. Yang et al. [22] synthesized the $\mathrm{Fe}_{5} \mathrm{C}_{2} /$ Co heterostructured nanoparticles (NPs) constructed by a secondary growth strategy, where the $\mathrm{Fe} / \mathrm{Co}$ molar ratio was tuned from 3.3 to 25. Based on the FTS reaction evaluation, they found that the incorporation of $0.6 \mathrm{wt} \% \mathrm{Co}(\mathrm{Fe} / \mathrm{Co}=12)$ increased the $\mathrm{Fe}_{5} \mathrm{C}_{2} / \mathrm{Co}$ catalyst activity by more than four times that of the pure $\mathrm{Fe}_{5} \mathrm{C}_{2}$ catalyst (CO conversion $5 \%$ ) at low 

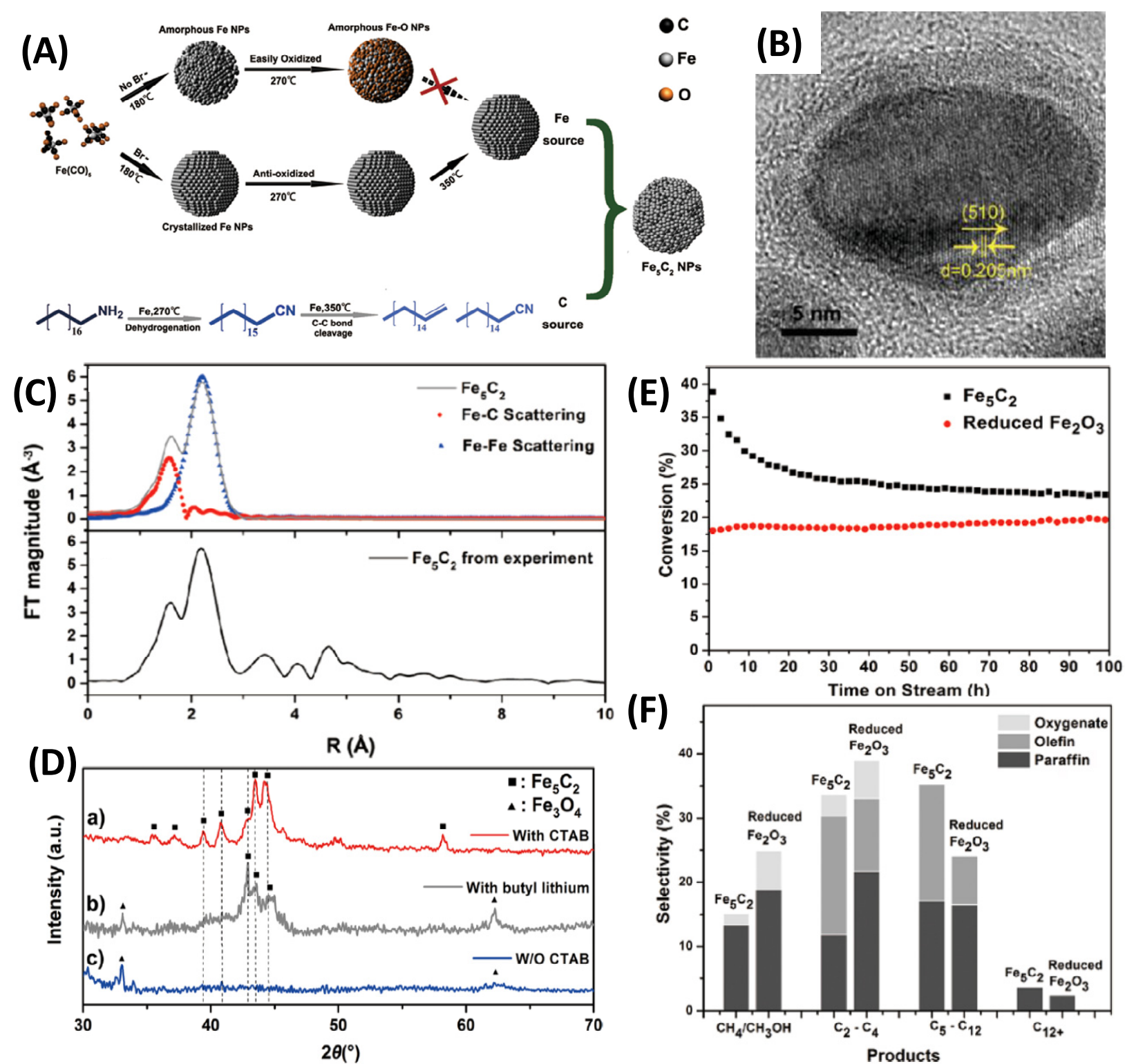

Fig. 2. (A) Schematic illustration of the formation mechanism of $\mathrm{Fe}_{5} \mathrm{C}_{2}$ nanoparticles (NPs). (B) HRTEM image of a single 20-nm $\mathrm{Fe}_{5} \mathrm{C}_{2} \mathrm{NP}$. (C) $\mathrm{Simu}_{-}$ lated Fourier transform (FT)-extended X-ray absorption fine structure (EXAFS) data for $\mathrm{Fe}_{5} \mathrm{C}_{2}$ (solid gray line) as a sum of contributions from carbon scattering (red $\bullet$ ) and iron scattering (blue $\boldsymbol{\Delta}$ ), and the experimental FT-EXAFS pattern obtained for the $\mathrm{Fe}_{5} \mathrm{C}_{2} \mathrm{NPs}$. (D) X-ray diffraction patterns for products generated from reactions with (a) bromide, (b) $n$-butyl lithium, or (c) neither. Overall catalytic performance of $\mathrm{Fe}_{5} \mathrm{C}_{2} \mathrm{NPs}_{2} / \mathrm{SiO}_{2}$ and reduced $\mathrm{Fe}_{2} \mathrm{O}_{3} / \mathrm{SiO}_{2}$ catalysts: (E) CO conversion and (F) product selectivity. Reproduced with permission from Ref. [2]. Copyright 2012, American Chemical Society.

temperature. The synergistic effect of both sites led to the catalyst having a similar product distribution to that of the Co catalyst because Co has a much lower energy barrier for CO dissociation compared with that of $\mathrm{FeC}_{x}$ and chain growth reaction can take place on the $\mathrm{FeC}_{x}$ sites at relatively low temperatures, as studied by pulse reaction.

The supports have also been researched, including $\mathrm{SiO}_{2}$ $[17,23,24], \mathrm{Nb}_{2} \mathrm{O}_{5}[6,25], \mathrm{TiO}_{2}[13,26], \mathrm{Al}_{2} \mathrm{O}_{3}$ [4], and CNT [27]. Because the strength of interaction between Co and the supports is different, particle size control plays a vital role when $\mathrm{SiO}_{2}, \mathrm{Al}_{2} \mathrm{O}_{3}$, and CNT are used as supports. For example, it has been found that the cause of the aggregation of cobalt nanoparticles during the synthesis of highly loaded silica-supported catalysts is the drying process after impregnation of the silica grains with the aqueous cobalt nitrate precursor (Fig. $3(\mathrm{~A})-(\mathrm{C})$ ) [24]. The maximal spacing of the $\mathrm{Co}_{3} \mathrm{O}_{4}$ nanoparticles was obtained by fluid-bed drying at $100^{\circ} \mathrm{C}$ in $\mathrm{N}_{2}$ flow, resulting from the silica support inside grains. This sample had high stability after $240 \mathrm{~h}$, showing little aggregation and particle sizes of 9-13 nm. For $\mathrm{Nb}_{2} \mathrm{O}_{5}$ and $\mathrm{TiO}_{2}$, the loading and synthesis method have a strong effect on the activity and selectivity. Three catalyst preparation procedures were reported for the preparation of $\mathrm{Co} / \mathrm{TiO}_{2}$ catalysts with $4-24 \mathrm{wt} \%$ Co (Fig. 3(D)-(E)): incipient wetness impregnation (IWI), deposition-precipitation using urea hydrolysis (DPU), and ammonia evaporation (DPA) [17]. The DPA catalysts displayed superior 
(A)

Impregnated

Calcined / Reduced
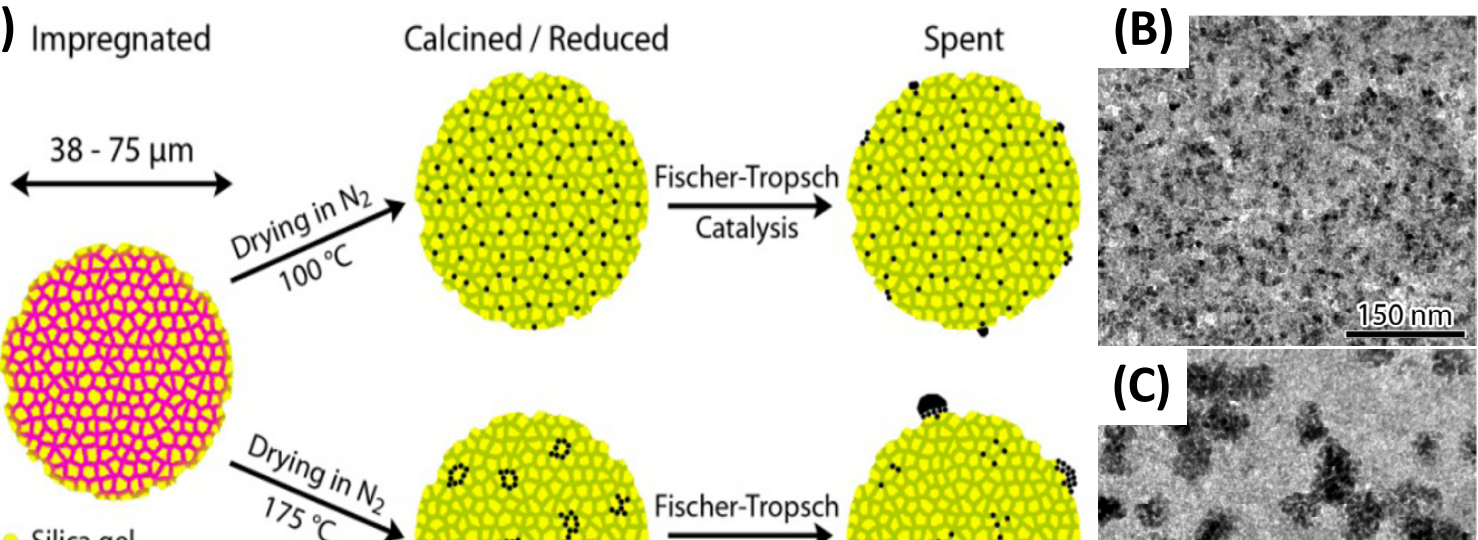

Silica gel

- Silica pore

- Cobalt nitrate

- Cobalt particle $(8-10 \mathrm{~nm})$

(D)
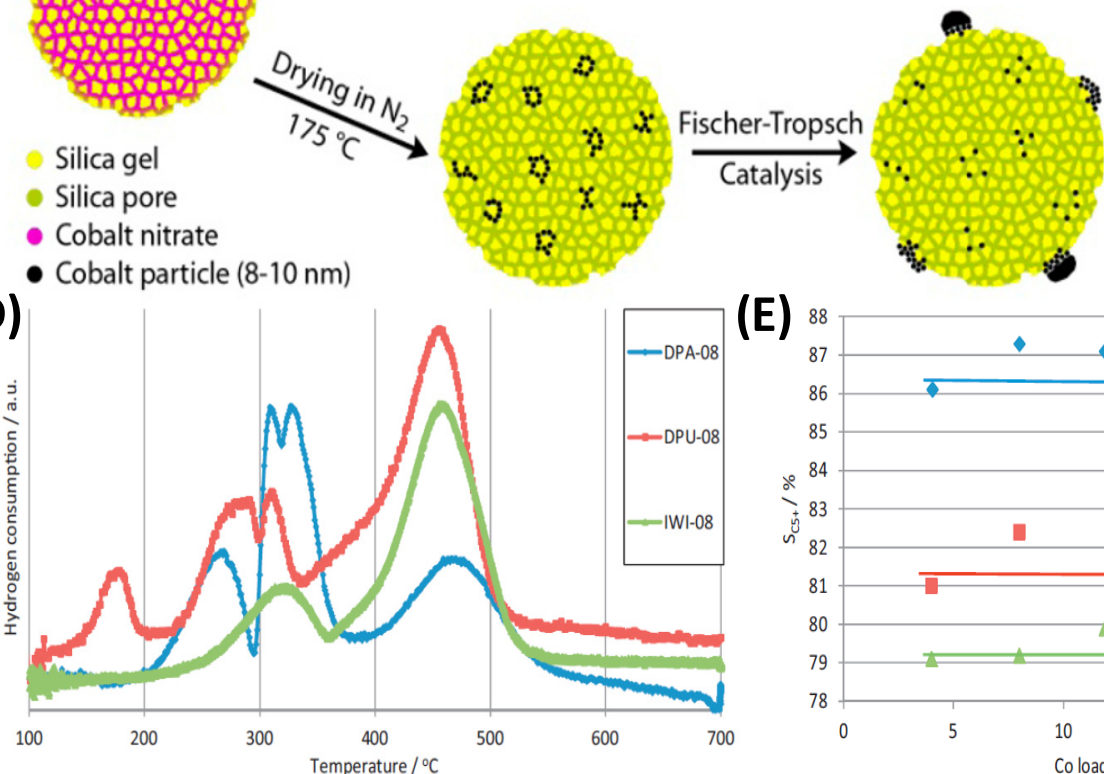

(C)

(E)

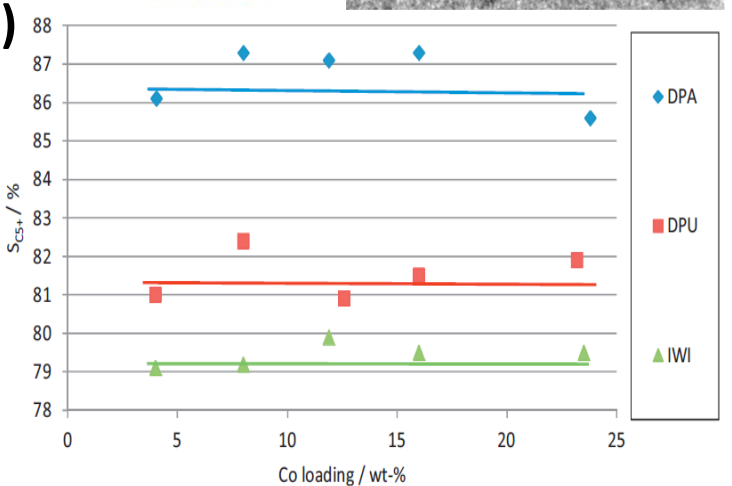

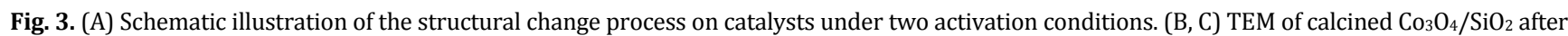
drying at 100 and $175{ }^{\circ}$ C. Reproduced with permission from Ref. [24]. Copyright 2014, American Chemical Society. (D) TPR profiles for Co/TiO 2 catalysts DPU-08, DPA-08, and IWI-08. (E) $\mathrm{C}_{5}$ selectivity at $2.0 \mathrm{MPa}, 220^{\circ} \mathrm{C}, \mathrm{H}_{2} / \mathrm{CO}=2.0$ for $\mathrm{Co} / \mathrm{TiO}_{2}$ catalysts prepared by different methods. Reproduced with permission from Ref. [17]. Copyright 2014, Elsevier.

activity and $\mathrm{C}_{5+}$ selectivity for the entire cobalt loading range studied.

\subsection{Determination of the mechanism}

To observe the reaction mechanism directly, in situ methods have been developed. In situ scanning tunneling microscopy (STM) was used by Navarro et al. [3] to monitor a cobalt model catalyst and gain further insight into the fundamental mechanism under reaction conditions. They found that the terraces of the cobalt catalyst were covered by parallel arrays of stripes after $30 \mathrm{~min}$ and proposed that the stripes are formed by the self-assembly of linear hydrocarbon product molecules, as indicated by the width of the stripes, which corresponds to molecules that are 14 or 15 carbon atoms long (Fig. 4). A simple model that explains the accumulation of such long molecules is based on monomer-by-monomer synthesis and explicitly accounts for their thermal desorption. Similarly, Liu et al. [21] applied in situ environmental (E) TEM to detect the formation of the iron carbide nuclei mentioned in Section 2.1.

Theoretical calculations are a common method to reveal structure-performance relationships. Zhang et al. [5] established a reactive force field for molecular dynamics (MD) stud- ies of the surface transformation of the cobalt (0001) surface induced by an overlayer of adsorbed carbon atoms. Significant surface reconstruction was observed with the upward movement of the Co atoms and some of the $\mathrm{C}$ atoms to positions below the surface. A driving force for the surface transformation is the preference of $\mathrm{C}$ adatoms to adsorb in 5- or 6-fold coordinated sites and the increasing strain in the surface because of the changes in surface metal-metal bond distances with the increasing surface overlayer concentration, which is dependent on the nanosize dimension of the surface covered with carbon. Then, Chen et al. [28] investigated the way in which the triple bond in $\mathrm{CO}$ dissociates on a Co catalyst. CO dissociation was probed by ${ }^{12} \mathrm{C}^{16} \mathrm{O} /{ }^{13} \mathrm{C}^{18} \mathrm{O}$ scrambling in the absence and presence of $\mathrm{H}_{2}$. The initial scrambling rate without $\mathrm{H}_{2}$ was significantly higher than the rate of CO consumption under CO hydrogenation conditions, as shown by temperature-programmed in situ IR spectroscopy, which indicated that the surface contained sites sufficiently reactive to dissociate $\mathrm{CO}$ without the assistance of $\mathrm{H}$ atoms. The positive $\mathrm{H}_{2}$ reaction order was correlated to the fact that the hydrogenation of adsorbed $\mathrm{C}$ and $\mathrm{O}$ atoms was slower than $\mathrm{CO}$ dissociation. A similar conclusion was also obtained by Joos et al. [29].

Based on the thermodynamically stable and terraced-like $\chi^{-}$ 

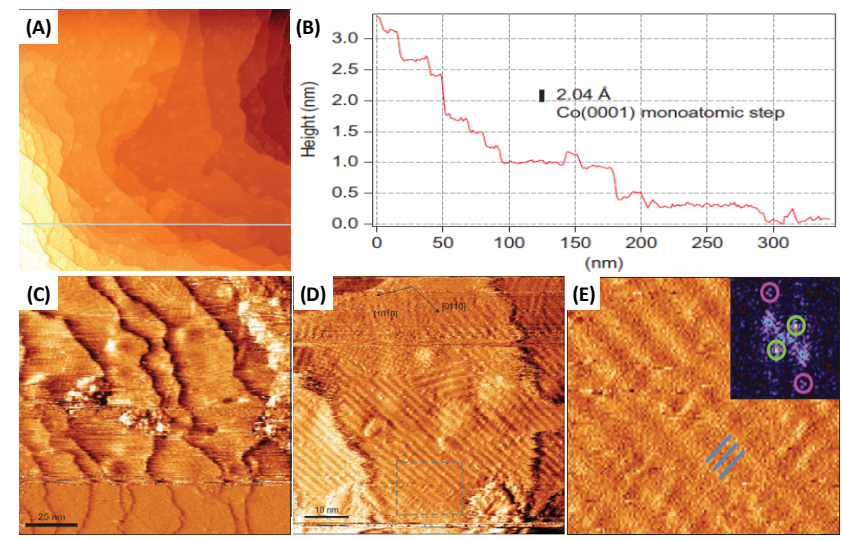

Fig. 4. (A) A $342 \times 342-\mathrm{nm}^{2}$ STM topographic image of clean Co(0001) at $221^{\circ} \mathrm{C}$ and in a mixture of hydrogen and argon $\left(\mathrm{PH}_{2}: \mathrm{PAr}=1: 4\right)$ at 4 bar. Inset: low energy electron diffraction (LEED) pattern of the clean crystal. (B) Height profile along the line indicated in (A). (C) A $130.7 \times$ $130.7 \mathrm{~nm}^{2}$ STM topographic image (derivative mode) of the cobalt surface at $221 \pm 10^{\circ} \mathrm{C}, 52 \mathrm{~min}$ after switching to a reactive $1: 2: 2$ gas mixture of carbon monoxide, hydrogen, and argon at a total pressure of $0.4 \mathrm{MPa}$. (D) $62 \times 62 \mathrm{~nm}^{2} \mathrm{STM}$ topography image of the cobalt surface at $221 \pm 10^{\circ} \mathrm{C}, 40 \mathrm{~min}$ after switching to a reactive 1:2:2 mixture of carbon monoxide, hydrogen, and argon at $0.4 \mathrm{MPa}$ total pressure. (E) An enlarged view of the $15 \times 12.5 \mathrm{~nm}^{2}$ region indicated by the dashed rectangle in (D). Inset: Fourier transform reflecting the main periodic structures in the image. Green circles highlight the peaks corresponding to the periodicity of the striped pattern $(1.8 \pm 0.3 \mathrm{~nm})$. Pink circles highlight the periodicity of the individual molecules within the stripes $(0.46$ $\pm 0.04 \mathrm{~nm})$. Reproduced with permission from Ref. [3]. Copyright 2014, Nature.

$\mathrm{Fe}_{5} \mathrm{C}_{2}$ (510), Pham et al. [30] studied the mechanisms of $\mathrm{CH}_{4}$ formation and $\mathrm{C} 1-\mathrm{C} 1$ coupling. The unfavorable formation of $\mathrm{CH}_{4}$ under FTS conditions resulted from the high effective barriers to $\mathrm{CH}_{4}$ formation. The $\mathrm{C}+\mathrm{CH}$ and $\mathrm{CH}+\mathrm{CH}$ are the most likely coupling pathways following the carbide mechanism. The effective barrier of $\mathrm{C} 1-\mathrm{C} 1$ coupling was lower than that of $\mathrm{CH}_{4}$ formation. Therefore, this surface shows unexpectedly high $\mathrm{C}_{2+}$ selectivity, which indicates that manipulating the crystal facets of the $\chi-\mathrm{Fe}_{5} \mathrm{C}_{2}$ catalyst could effectively tune the FTS selectivity.

\section{Syngas conversion to unsaturated hydrocarbons}

\subsection{Olefins}

Olefins, usually meaning lower olefins (such as ethylene, propylene, and butylene), have been utilized to basic building blocks in the chemical industry and are traditionally produced from the thermal or catalytic cracking of naphtha and oil in the refining process. Recently, the direct production of lower olefins from syngas has attracted much attention given supply limitations and environmental issues (Table 1).

Compared to Co-based catalysts, Fe-based catalysts have drawn much attention because the product from syngas conversion contains more olefins. Galvis et al. [9] synthesized catalysts comprising Fe nanoparticles (promoted by $\mathrm{S}$ and $\mathrm{Na}$ ) homogeneously dispersed on weakly interactive $\alpha-\mathrm{Al}_{2} \mathrm{O}_{3}$ or carbon nanofiber (CNF) supports. The Fe-supported catalysts were prepared by the multi-step incipient wetness impregnation of the selected support $\left(\alpha-\mathrm{Al}_{2} \mathrm{O}_{3}, \beta-\mathrm{SiC}, \gamma-\mathrm{Al}_{2} \mathrm{O}_{3}, \mathrm{SiO}_{2}\right.$, or $\mathrm{CNF}$ ) with an aqueous solution of ammonium iron citrate contained low amounts of sulfur and sodium. Catalytic tests were performed at $340{ }^{\circ} \mathrm{C}$ and $2.0 \mathrm{MPa}$ with a $\mathrm{H}_{2} / \mathrm{CO}$ ratio of 1 after $64 \mathrm{~h}$ on stream, and the Fe/CNF sample displayed a high $\mathrm{C}_{2}-\mathrm{C}_{4}$ olefin selectivity (52\%) that could be increased to $61 \%$ if the pressure was change to $0.1 \mathrm{MPa}$ (Fig. 5). They found that the methanation reaction was suppressed by the promoters $(\mathrm{Na}$ and S) when using "inert" CNF and $\alpha-\mathrm{Al}_{2} \mathrm{O}_{3}$ supports, which favor the proximity between iron and promoters. Through Mössbauer spectroscopy and TEM observation, the active iron phase was found to be iron carbide, and the particles only grew during the first $4 \mathrm{~h}$ of reaction at catalyst activation and initial usage.

Then, based on the Fe-Na-S/CNF $\left(\alpha-\mathrm{Al}_{2} \mathrm{O}_{3}\right)$ catalyst, Galvis et al. [31] continued to try to promote the performance and study the structure-performance relationship of the best catalyst. First, different iron precursor salts were used to investigate the effects on the size of iron nanoparticles. Through tests under industrially relevant conditions $\left(340{ }^{\circ} \mathrm{C}, 2.0 \mathrm{MPa}\right.$, and $\mathrm{H}_{2} / \mathrm{CO}=$ $1 \mathrm{v} / \mathrm{v}$ ), the catalyst synthesized with ammonium iron citrate not only displayed high selectivity to lower olefins (>50\% C) but also a higher catalytic activity and a much lower rate of carbon lay-down (by a factor of 4-6) compared to the sample prepared with other precursors. Several ordered mesoporous materials with a comparable pore size and pore symmetry have been used as model supports by Oschatz et al. [32,33]. Ordered mesoporous carbon (CMK-3) as a support possesses higher activity $\left(7.5 \times 10^{-6}\right.$ molco $\left._{\mathrm{Fe}^{-1}} \mathrm{~s}^{-1}\right)$ and $\mathrm{C}_{2}-\mathrm{C}_{4}$ olefin selectivity $(\sim 60 \%)$ than those of ordered mesoporous silica (SBA-15) and ordered mesoporous silicon carbide (OM-SiC) as a support under FTO conditions of $350{ }^{\circ} \mathrm{C}, 0.1 \mathrm{MPa}, \mathrm{H}_{2} / \mathrm{CO}=1$, and a gas

Table 1

Compilation of catalytic performance data for a variety of Fe/Co catalysts active for the FTO.

\begin{tabular}{|c|c|c|c|c|c|}
\hline Catalyst & Temperature $/{ }^{\circ} \mathrm{C}$ & Pressure/MPa & CO conversion $/ \%$ & $\mathrm{C}_{2}-\mathrm{C}_{4}$ olefin selectivity $/ \%$ & Ref. \\
\hline $\mathrm{Fe} / \mathrm{CNF}$ & 340 & 2.0 & 7.0 & 52.0 & [9] \\
\hline $\mathrm{FeK}_{1} / \mathrm{rGO}$ & 340 & 2.0 & 60.0 & 62.0 & [14] \\
\hline $\mathrm{Fe} / \mathrm{NG}_{-} 16.4$ & 340 & 0.5 & 1.4 & 48.2 & [39] \\
\hline Pod-Fe & 320 & 0.5 & 1.3 & 38.9 & [40] \\
\hline $\mathrm{Fe} / \mathrm{S} 80-\mathrm{E}$ & 320 & 1.0 & 63.4 & 46.2 & [41] \\
\hline FeMn/S80-E & 300 & 1.0 & 50.5 & 54.6 & [42] \\
\hline Fe-10MnK-AC & 300 & 2.0 & 85.0 & 39.4 & [43] \\
\hline $\mathrm{FeBi} / \mathrm{SiO}_{2}$ & 350 & 0.1 & 17.0 & 53.0 & [44] \\
\hline Cartridge 1 & 350 & 0.1 & 4.3 & 6.7 & [45] \\
\hline
\end{tabular}




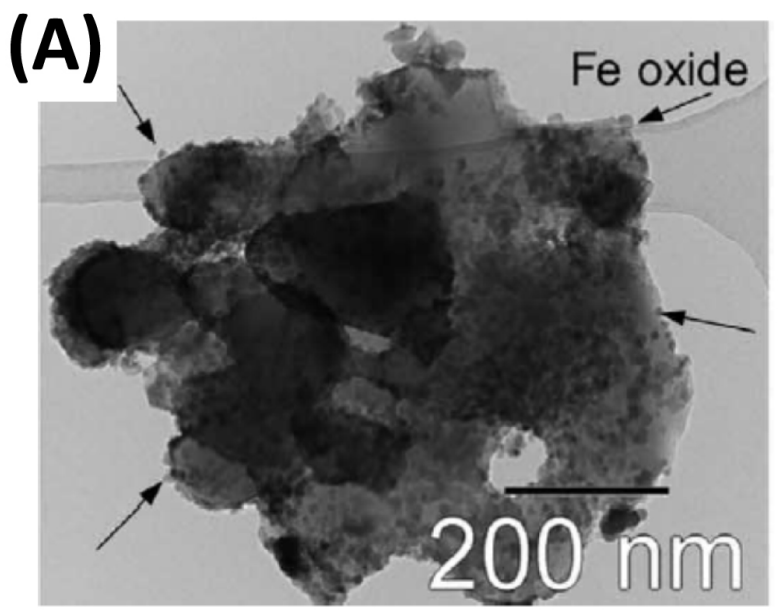

(C)

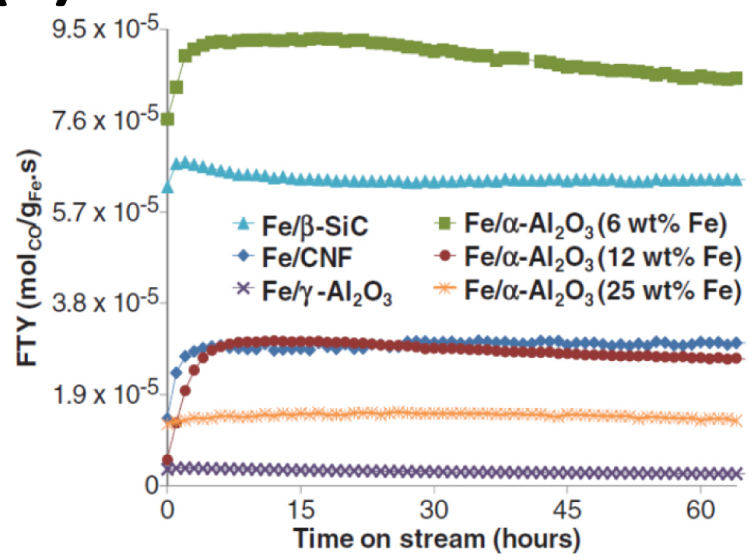

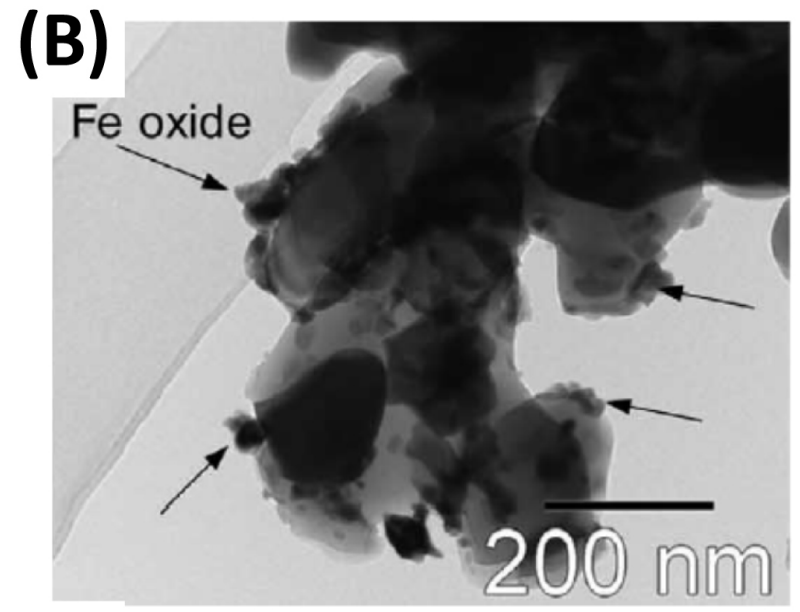

(D)

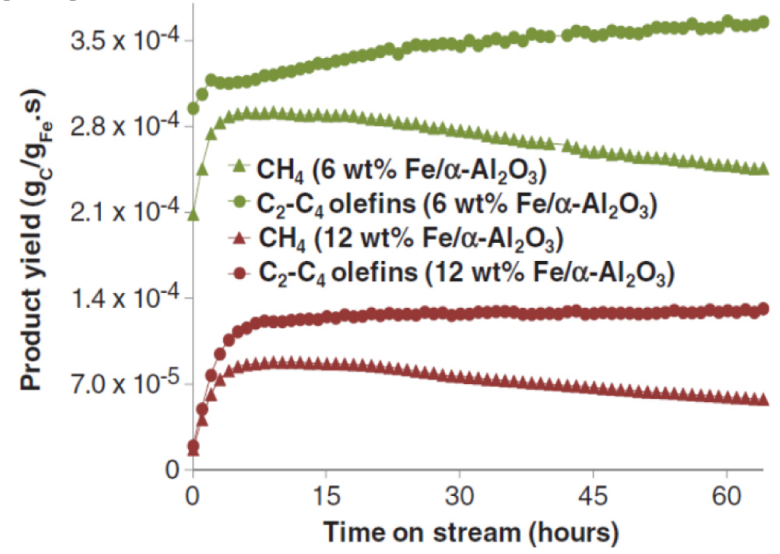

Fig. 5. (A, B) The images from the fresh $\mathrm{Fe} / \alpha-\mathrm{Al}_{2} \mathrm{O}_{3}$ catalysts and the spent catalysts after $64 \mathrm{~h}$ of reaction at $340{ }^{\circ} \mathrm{C}, 2.0 \mathrm{MPa}$, and a $\mathrm{H}_{2} / \mathrm{CO}$ ratio of $1 .(\mathrm{C})$ Iron time yield is plotted above as a function of time for Fe-supported catalysts. (D) Methane and lower olefins yields are plotted as a function of time for Fe-supported catalysts. Reproduced with permission from Ref. [9]. Copyright 2012, Science.

hourly space velocity (GHSV) of $1800 \mathrm{~h}^{-1}$. Nitrogen surface functionalization and the removal of surface groups on CMK-3 could further increase the activity of the catalysts in the presence of promoters. Subsequently, the effects of the calcination conditions on CMK-3 were investigated [34]. After testing under industrially relevant FTO conditions, the samples calcined at 300 and $500{ }^{\circ} \mathrm{C}$ showed higher olefin selectivities $(50.4 \%$ and $54.6 \%$, respectively) than those of samples calcined at 800 and $1000{ }^{\circ} \mathrm{C}$. Through XRD, TEM, and energy dispersive X-ray (EDS) spectroscopy elemental mapping, they found that a low calcination temperature led to a small particle size and low carbon deposition rate, although a high calcination temperature led to a higher ratio of catalytically active iron (carbide) species. Recently, to modulate $\mathrm{Na}$ and $\mathrm{S}$ promotors precisely, Casavola et al. [35] exchanged organic ligands adsorbed on the surface of iron oxide catalysts with inorganic species such as $\mathrm{Na}_{2} \mathrm{~S}$. This was carried out not only to provide an active surface but also to introduce controlled amounts of $\mathrm{Na}$ and $\mathrm{S}$, which act as promoters for the catalytic process.

Through previous research, the de Jong group determined that the size of the iron particles was the key factor affecting performance and deactivation. The particle size was controlled from 3 to $9 \mathrm{~nm}$, and the samples were investigated under industrially relevant conditions $\left(340^{\circ} \mathrm{C}, 2.0 \mathrm{MPa}\right.$, and $\left.\mathrm{H}_{2} / \mathrm{CO}=1\right)$ by Galvis et al. [7] and Xie et al. [36]. For the supported iron catalysts, iron particle growth may result in loss of catalytic activity over time, as shown by HRTEM observation. Upon the addition of promoters to the iron nanoparticles supported on carbon nanofibers, the initial catalytic activities were high. However, substantial deactivation was observed over a period of $100 \mathrm{~h}$, along with an increase in Fe particle size to $20-50 \mathrm{~nm}$, thereby supporting the proposal that the loss of active Fe surface area was the main cause of deactivation (Fig. 6(A) and (B)). Later, steady-state isotopic transient kinetic analysis and density functional theory (DFT) were also used by Xie et al. [37] to obtain a fundamental understanding and determine the coverage and residence times for reactive species on supported iron carbide particles, as well as $\mathrm{H}$ adsorption. The fitting of $\mathrm{CH}_{4}$ response curves revealed the presence of parallel side-pools of reacting carbon. Hence, on $\mathrm{Na}_{2} \mathrm{~S}$-promoted $\mathrm{Fe}_{5} \mathrm{C}_{2}$ surfaces, the adsorption on carbon sites is weaker and adsorption on iron sites is stronger, which is consistent with the lower $\mathrm{H}$ coverage, lower $\mathrm{CH}_{4}$ formation, and greater olefin formation (Fig. 6(C) and (D)). Meanwhile, Koeken et al. [38] were the first group to 


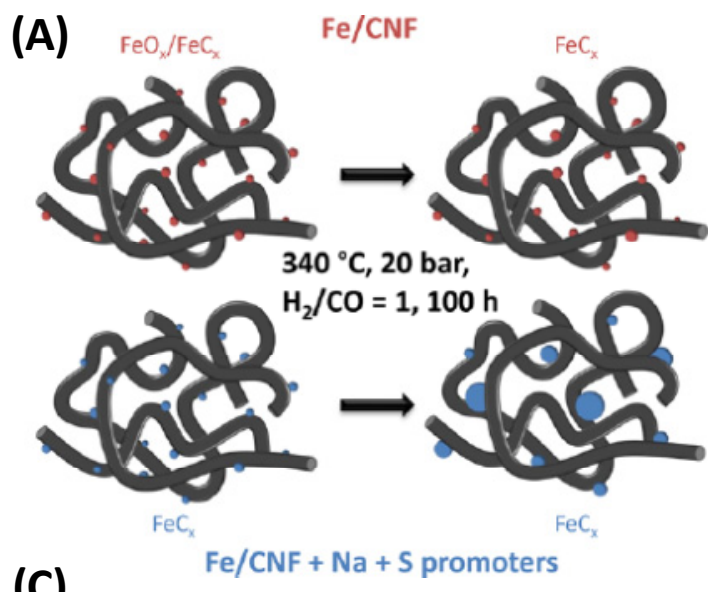

(C)

(B)
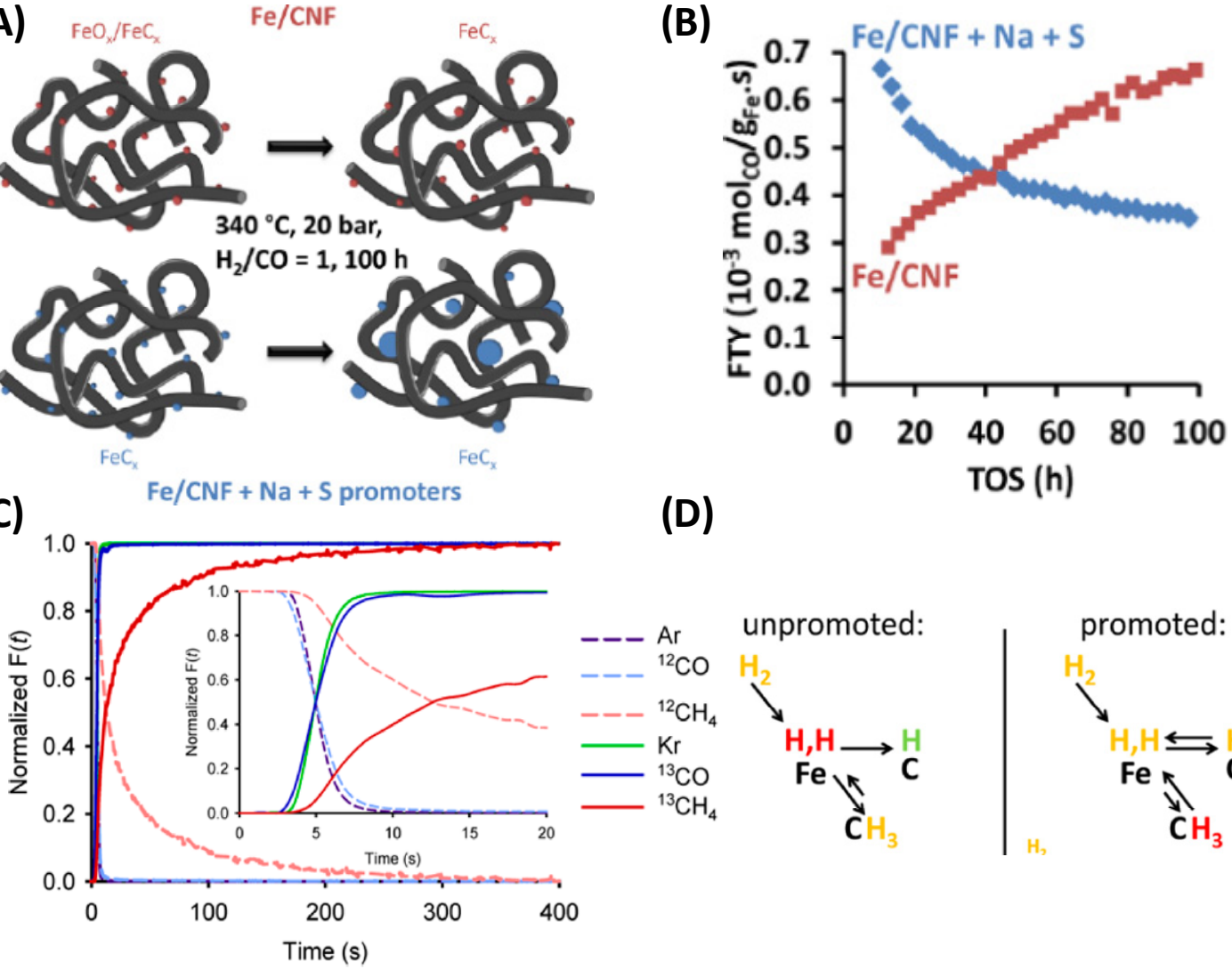

unpromoted:

promoted:
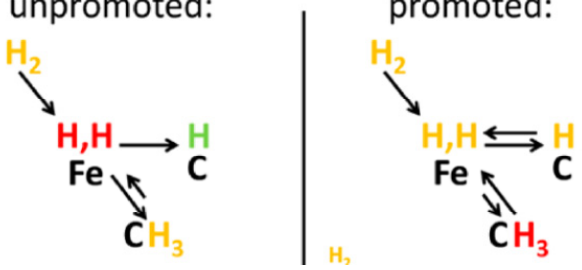

Fig. 6. (A) Schematic illustration of the change in the nanoparticle size, including the effect of promoters, after reaction. (B) Iron time yield (FTY) of non-promoted catalysts and promoted catalysts. Reproduced with permission from Ref. [36]. Copyright 2016, American Chemical Society. (C) Typical normalized transient curves of the full period and initial period (inset) from ${ }^{13} \mathrm{CO} / \mathrm{H}_{2} / \mathrm{Kr}$ to ${ }^{12} \mathrm{CO} / \mathrm{H}_{2} / \mathrm{Ar}$. (D) Cartoon of the promoter effect by $\mathrm{Na}_{2} \mathrm{~S}$. The colors of the hydrogen atoms denote their energy: red, yellow, and green denote high, medium, and low energy, respectively. The blue shapes denote the $\mathrm{Na}_{2} \mathrm{~S}$ species. The promoter increases the $\mathrm{H}$ adsorption strength on iron and decreases the adsorption on carbon, thereby decreasing methane formation and increasing olefin formation. Reproduced with permission from Ref. [37]. Copyright 2016, American Chemical Society.

apply the tapered-element oscillating microbalance (TEOM) to FTS research to investigate the process of carbon deposition. They obtained in situ information concerning the carbon deposition occurring during high-temperature FTS processes in combination with on-line product analysis. By calculating the rate of mass increase, they found that increasing the $\mathrm{H}_{2}$ partial pressure or total pressure reduced the rate of carbon deposition.

Several specific Fe-based-catalyst-modulating supports and promoters have been developed. Chen et al. [39] applied graphene materials to support iron: N-doped graphene was used as an efficient electron donor and resulted in a high selectivity of around 50\% for light olefins [39]; Fe nanoparticles encapsulated in pod-like carbon nanotubes gave a high selectivity of light olefins (45\%) and high stability over $120 \mathrm{~h}$ reaction because of the agglomeration of Fe nanoparticles and carbon deposition was suppressed [40]. Liu et al. [41,42] utilized macroporous silica $(80 \mathrm{~nm})$ modified with ethylene glycol as a support, which showed high selectivity for light olefins (46.2 mol\%), as well as high activity (CO conversion 63.4\%), because of the high diffusion efficiency and highly dispersed iron particles. Cheng et al. [14] focused on a systematic study on the effect of $\mathrm{K}$ in the reduced graphene oxide (rGO) supported iron catalysts on the catalytic performance in FTO. Unlike the reduction of the activity, the selectivity to lower olefins increased steadily with increasing $\mathrm{K}$, giving the highest selectivity to lower olefins of $68 \%$ and an olefin/paraffin $(\mathrm{O} / \mathrm{P})$ ratio of 11 in the $\mathrm{C}_{2}-\mathrm{C}_{4}$ hydrocarbons over the $\mathrm{FeK}_{2} / \mathrm{rGO}$ catalyst. Tian et al. [43] used $\mathrm{KMnO}_{4}$ as a precursor and the support was coated uniformly with $\mathrm{K}$-doped birnessite $\mathrm{MnO}_{2}$, which acted not only as a structural promoter to anchor $\mathrm{Fe}_{2} \mathrm{O}_{3}$ nanoparticles but also as competition for $\mathrm{H}_{2}$ adsorption, thus decreasing the $\mathrm{H}_{2} / \mathrm{CO}$ ratio over active sites and reducing the possibility of further hydrogenation of olefins. Similarly, recently, Ordomsky et al. [44] showed that $\mathrm{Bi}$ and $\mathrm{Pb}$, metals typically used in soldering, acted as promoters and facilitate $\mathrm{CO}$ dissociation by removing $\mathrm{O}$ atoms from iron carbide, resulting in a remarkable increase in the light olefin production rate. Recently, Lødeng et al. [45] tried to synthesize catalytic cartridges made from anodized $\mathrm{Al}$ plates ( $\left.\mathrm{FeO}_{x} / \mathrm{AAO}-\mathrm{Al}\right)$ for FTO, but the performance was unsatisfactory, having low olefin selectivity $(<5 \%)$ and yield $(<1 \%)$.

Zhai et al. [15] synthesized Zn- and Na-modulated Fe catalysts by a simple coprecipitation/washing method. Based on performance comparison, the Fe-Zn-0.81Na catalyst showed the best performance with a CO conversion of $77.2 \%$ and olefin selectivity of $58 \%$, which originated from not only the great 
change of iron species size induced by $\mathrm{Zn}$ but also changes to the electronic structure induced by $\mathrm{Na}$. By a combination of in situ X-ray photoelectron spectroscopy (XPS), pulse experiments, and DFT calculations, it was found that delocalized electrons were transferred from $\mathrm{Na}$ to $\mathrm{Fe}$ when the $\mathrm{Na}$ ion was distributed on the surface of $\mathrm{Fe}_{5} \mathrm{C}_{2}$, making the surface iron carbide species electron rich, which suppressed the hydrogenation of double bonds and promoted the desorption of the products.

Research into Co-based catalysts has rarely been reported because of their strong hydrogenation capacity. Qi et al. [46] combined experimental kinetic studies with theoretical calculations to reveal the factor dominating the olefin-to-paraffin ratio in Co-catalyzed FTS. The calculated olefin to paraffin ratio decreases with chain length, except for ethylene, which agrees well with the experimental results. They found that the carbon number was dependent on the adsorption energies of olefin rather than the activation energies of their hydrogenation reactions.

$\mathrm{Co}_{2} \mathrm{C}$ is usually regarded as the inactive phase toward syngas conversion, but several recent works have made significant breakthroughs. Zhong et al. [8] prepared a cobalt-manganese composite oxide (CoMn catalyst) and investigated it for the FTO reaction under mild reaction conditions $\left(250^{\circ} \mathrm{C}, 0.1 \mathrm{MPa}\right.$, and a $\mathrm{H}_{2} / \mathrm{CO}$ ratio of 2) (Fig. 7). This catalyst, after reaching the steady state, displayed a high selectivity for the production of lower olefins $(60.8 \mathrm{C} \%)$ and a low methane selectivity $(5.0 \mathrm{C} \%)$ at a $\mathrm{CO}$ conversion of $31.8 \%$. The most interesting feature was that the $\ln \left(\mathrm{W}_{n} / n\right)$ value of $\mathrm{C}_{1}$ was higher than that of $\mathrm{C}_{2}$ at the beginning $\left(\mathrm{W}_{n}\right.$ is the fraction, by weight, of a carbon product with $n$ carbon atoms), but the $\ln \left(\mathrm{W}_{n} / n\right)$ values of $\mathrm{C}_{1}$ and $\mathrm{C}_{2}$ were similar after $10 \mathrm{~h}$, and the $\ln \left(\mathrm{W}_{n} / n\right)$ value of $\mathrm{C}_{3}$ was the highest, consistent with the highest selectivity for $\mathrm{C}_{3}$ product.
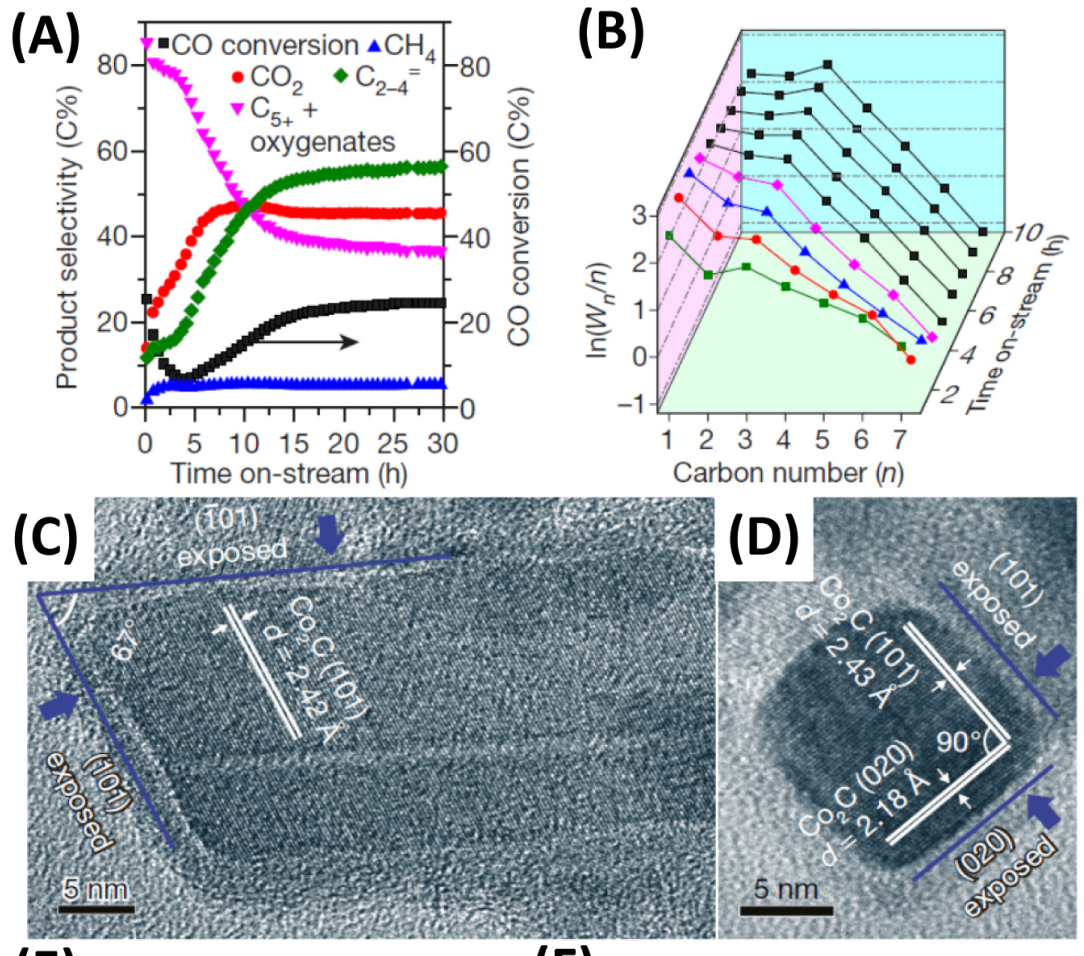

(E)

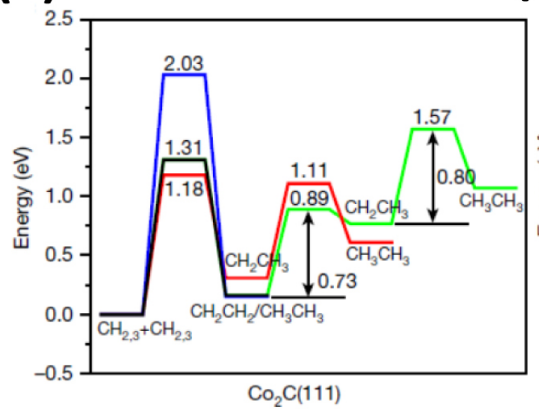

(F)

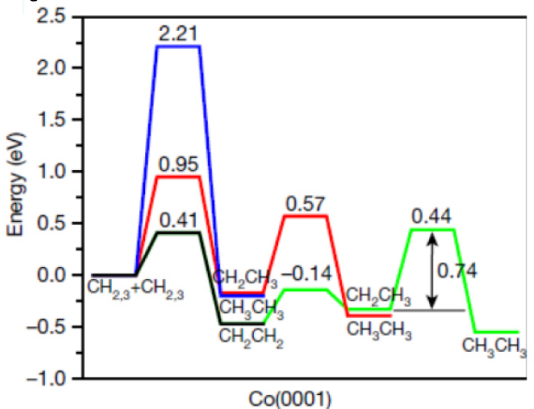

Fig. 7. (A) CO conversion and product selectivity as a function of time-on-stream. (B) Product plots $\left(\ln \left(\mathrm{W}_{n} / n\right)\right.$ and $\left.n\right)$ versus time-on-stream. (C, D) High-resolution images of $\mathrm{Co}_{2} \mathrm{C}$ nanoprisms with exposed (101), (-101), and (020) facets. (E, F) Energy profiles for pathways that lead to the formation of $\mathrm{CH}_{2} \mathrm{CH}_{2}$ and $\mathrm{CH}_{3} \mathrm{CH}_{3}$ on the $\mathrm{Co}_{2} \mathrm{C}(111)$ surface of $\mathrm{Co}_{2} \mathrm{C}$ and the $\mathrm{Co}(0001)$ surface of Co. Reproduced with permission from Ref. [8]. Copyright 2017, Nature. 
This phenomenon, which is different from that of the typical cobalt-based Fischer-Tropsch catalyst, was attributed to the $\mathrm{Co}_{2} \mathrm{C}$ nanoprisms formed by interaction with alkali elements and manganese, as indicated by HRTEM and EDS measurements. DFT calculations were used to examine three possible paths to $\mathrm{CH}_{3} \mathrm{CH}_{3}$ formation on the $\mathrm{Co}_{2} \mathrm{C}$ (101), $\mathrm{Co}_{2} \mathrm{C}(020), \mathrm{Co}_{2} \mathrm{C}$ (111), and Co (0001) surfaces, respectively, as well as two paths to $\mathrm{CH}_{2} \mathrm{CH}_{2}$ formation. $\mathrm{Co}_{2} \mathrm{C}$ nanoprisms formed from the initial catalyst preferentially exposed the $\{101\}$ or $\{020\}$ facets, which exhibit high selectivity to olefins and low selectivity to methane.

\subsection{Aromatics}

Aromatics, mainly produced from petroleum refinement processes, are used as fuel additives and are important platform molecules for the polymer industry. Direct synthesis of aromatics from syngas requires high energy efficiency and low $\mathrm{CO}_{2}$ emissions, making this process more competitive than the methanol-to-aromatics (MTA) process, which is challenging because of the severe operating conditions and low yield of aromatics. Because of the structural similarity between olefins and aromatics, the catalysts for aromatics are usually based on the FTO catalysts accompanied with molecular sieves, which provide acidic sites for cyclization [47]. Therefore, recent works have mainly concentrated on Fe-based catalysts. In 2014, Yan et al. [48] investigated the effect of Pd as a promoter on Fe/HZSM-5 catalyst and optimized performance with temperature, pressure, and GHSV. Yang et al. [49] prepared a composite catalyst comprising a mixture of $\mathrm{Fe}_{2} \mathrm{O}_{3}-\mathrm{SiO}_{2}$ and Nb-/Ni-modified HZSM-5 (HZ) that showed high selectivity for benzene, toluene, and xylene (BTX, 30\%), while $\mathrm{CuO}-\mathrm{ZnO}-\mathrm{Al}_{2} \mathrm{O}_{3}$ (CZA)/modified-HZ had high selectivity for durene $(\sim 31 \%)$. The diverse distribution of aromatics was a result of the different reaction pathways, where alkenes and methanol were the intermediates on $\mathrm{Fe} / \mathrm{Ni}-\mathrm{HZ}$ and $\mathrm{CZA} / \mathrm{Ni}-\mathrm{HZ}$, respectively. Zhao et al. [50] combined a $\mathrm{Na}-\mathrm{Zn}-\mathrm{Fe}_{5} \mathrm{C}_{2}$ catalyst that had been applied to FTO previously with hierarchical HZSM-5, resulting in 51\% aromatic selectivity in the stable stage with CO conversion greater than $85 \%$. The appropriate density and strength of the Brønsted acid sites and the hierarchical pore structure of HZSM- 5 was tuned by controlling the alkali treatment conditions, as characterized by HRTEM, Brunauer-Emmett-Teller (BET), and NMR measurements, and the degree of ion exchange endowed the catalyst with an un- precedented aromatic yield.

\section{Syngas conversion to higher alcohols}

A wide variety of heterogeneous catalysts have been evaluated in the direct conversion of syngas into oxygenates (mainly higher alcohols). Generally, higher alcohol synthesis (HAS) catalysts can be classified into four categories: Rh-based, Mo-based, modified FTS (Fe/Co), and modified methanol synthesis (MS) systems. However, research into modified FTS catalysts has been the most extensive among the materials for HAS. According to the mechanistic basis of HAS in relation to FTS and MS, there must be an active component for carbonyl insertion, although traditional $\mathrm{Fe} / \mathrm{Co}$ catalysts hardly form higher alcohols (Table 2). Even in the presence of two or more active elements, further tuning of their electronic and geometric properties by the use of promoters and supports is necessary. Now, we discuss the recent progress achieved in the alternative catalyst synthesis routes and speculation of the mechanism.

\subsection{Iron catalysts}

The discovery of the production of oxygenates with Fe-based catalysts from syngas dates back to the pioneering work of Fischer and Tropsch. They chose a potassium-promoted iron catalyst for their experiments and found the oily product fraction contained oxygenates. Later, Kiennemann and coworkers $[10,12]$ published works on the effect of Dy and $\mathrm{La}$ on $\mathrm{Fe} / \mathrm{SiO}_{2}, \mathrm{FeCu} / \mathrm{SiO}_{2}$, or $\mathrm{Fe}-\mathrm{Cu}-\mathrm{Mo}-\mathrm{U}$ catalysts prepared via co-precipitation. $\mathrm{Fe}$ is accepted to be involved in the dissociative adsorption of $\mathrm{CO}$ and providing carbon chain growth site, but $\mathrm{Cu}$ has been indicated to provide $\mathrm{CO}$ insertion sites, facilitating the molecular adsorption of CO.

The preparation of these catalysts has been a research hotspot because the synthesis of higher alcohols requires the synergistic effect of Fe and $\mathrm{Cu}$. Bao et al. [51] and Pei et al. [52] tested a $\mathrm{Cu}-\mathrm{Fe}$ catalyst prepared by a co-precipitation method from $\mathrm{Cu}-\mathrm{Fe}$ composite oxides with a molar $\mathrm{Fe} / \mathrm{Cu}$ ratio of 0.05-0.67 at variable GHSV and temperature. The authors highlighted the high selectivity to $\mathrm{C}_{2+} \mathrm{OH}(90.1 \%)$ and $\mathrm{C}_{6+} \mathrm{OH}$ (53.4\%) in the alcohol distribution. The lower reaction temperature and higher GHSV increased the total alcohol selectivity, indicating that there was a visible dehydration reaction of alcohol into hydrocarbons. In the same year, Xiao et al. [18]

Table 2

Compilation of catalytic performance data for a variety of Fe/Co catalysts active for HAS.

\begin{tabular}{|c|c|c|c|c|c|c|}
\hline Catalyst & Temperature $/{ }^{\circ} \mathrm{C}$ & Pressure/MPa & CO conversion $/ \%$ & Total alcohol selectivity/\% & Higher alcohol selectivity/\% & Ref. \\
\hline $\mathrm{Co}_{4} \mathrm{Mn}_{1} \mathrm{~K}_{0.1}$ & 220 & 4.0 & 34.0 & 44.0 & 22.0 & [11] \\
\hline CuFe bimetallic NPs & 220 & 6.0 & 17.1 & 21.9 & 90.5 & [18] \\
\hline $\mathrm{Cu}_{10} \mathrm{Fe}_{1}$ & 210 & 6.0 & 29.7 & 27.3 & 90.1 & [51] \\
\hline $3 \mathrm{DOM} \mathrm{Cu}_{2} \mathrm{Fe}_{1}$ & 260 & 4.8 & 57.0 & 30.0 & 80.0 & [55] \\
\hline S2-CuFeMg-Cat & 300 & 4.0 & 56.9 & 49.1 & 11.3 & [56] \\
\hline $\mathrm{Cu}-\mathrm{Fe}-\mathrm{K}-\mathrm{M}_{80}$ & 320 & 5.0 & 56.0 & 63.0 & 72.3 & [57] \\
\hline $\mathrm{FeCuMn} 1.0 \mathrm{ZnO}$ & 260 & 4.0 & 26.4 & 57.0 & 61.7 & [59] \\
\hline $\mathrm{Cu}-\mathrm{Fe} / \mathrm{SiO}_{2}-\mathrm{N}$ & 250 & 3.0 & 17.4 & 28.6 & 30.1 & [61] \\
\hline $\mathrm{Cu} @(C u C o-a l l o y) / \mathrm{Al}_{2} \mathrm{O}_{3}$ & 220 & 2.0 & 21.5 & 50.6 & 48.9 & [69] \\
\hline $\mathrm{Co}_{1} \mathrm{Ga}_{0.6}-\mathrm{ZnAl}-\mathrm{LDO} / \gamma-\mathrm{Al}_{2} \mathrm{O}_{3}$ & 260 & 3.0 & 43.5 & 59.0 & 92.8 & [71] \\
\hline
\end{tabular}


investigated $\mathrm{Cu}$-Fe bimetallic nanoparticles synthesized by the co-reduction method as model catalysts. The $1 \mathrm{Cu} 3 \mathrm{Fe}$ sample showed the best performance, having a high selectivity to $\mathrm{C}_{6+} \mathrm{OH}(73.7 \%)$ that exceeded that the physical mixture of $\mathrm{Fe}$ and $\mathrm{Cu}$ nanoparticles. They considered that the $\mathrm{Cu}-\mathrm{FeC}_{x}$ center benefited alcohol formation, which led to higher selectivity to total alcohol. Subsequently, based on this research, they evaluated the performance in a 288-h test for higher alcohol synthesis deactivation studies. [53] During the reaction, the CO conversion and higher alcohol (HA) selectivity dropped from $17 \%$ to $14 \%$ and from $22 \%$ to $13 \%$, respectively. This change was explained by the structural evolution of $\mathrm{CuFe}$ bimetallic nanoparticles during reaction. Phase separation of the $\mathrm{Cu}$ and $\mathrm{Fe}$ components was observed directly by TEM, scanning tunneling electron microscopy (STEM)-EDS, and MES. The fresh sample originally contained spherical NPs homogeneously composed of $\mathrm{Cu}$ and $\mathrm{Fe}$ and underwent phase separation during the reaction, leading to the formation of $\mathrm{Fe}_{3} \mathrm{O}_{4}$ and severely sintered $\mathrm{Cu}$ particles.

Lu et al. [54] recently synthesized a 3DOM FeCu catalyst with variable metal ratio via the glyoxylate route. The catalyst with molar $\mathrm{Fe} / \mathrm{Cu}=0.5$ showed the highest surface area and the best performance (total alcohol selectivity $=31 \%$ and $\mathrm{C}_{6+}$ alcohols selectivity $=63 \%$ ); this is significantly superior to an analog prepared by co-precipitation. The authors rationalized the catalytic data based on three main factors: (1) the unique ordered structure has a large pore size, and the interconnected macroporous tunnels of the catalyst with a large accessible surface area improves the catalytic activity; (2) the atomic steps on the $\mathrm{Cu}$ surface originating from planar defects and lattice strain, as indicated by HRTEM (Fig. 8(A)-(C)); (3) the formation of the glyoxylate dianion eased the generation of high-density and uniformly distributed defective $\mathrm{Cu}^{0}$ and $\mathrm{Fe}_{5} \mathrm{C}_{2}$ NPs, as visualized by HRTEM and STEM-EDS mapping. To reveal the structure-performance relationship, the authors observed the catalyst structure through MES, in situ XPS, and in situ XAFS and established the possible reaction pathway through DFT calculations [55]. They found that the $d$-band center close to the Fermi level of $\mathrm{Cu}^{0}-\chi-\mathrm{Fe}_{5} \mathrm{C}_{2}$ (510) surface and the electron-rich interface of $\mathrm{Cu}^{0}-\chi-\mathrm{Fe}_{5} \mathrm{C}_{2}(510)$ arising from the delocalized electron transfer from $\mathrm{Cu}^{0}$ atoms facilitated $\mathrm{CO}$ activation and $\mathrm{CO}$ insertion into alkyl species to $\mathrm{C}_{2}$-oxygenates, thus enhancing the $\mathrm{C}_{2} \mathrm{H}_{5} \mathrm{OH}$ selectivity (Fig. 8(D)). Moreover, starting from $\mathrm{CHCO}$ intermediate, the proposed reaction pathway for $\mathrm{CO}$ hydrogenation to $\mathrm{C}_{2} \mathrm{H}_{5} \mathrm{OH}$ is $\mathrm{CHCO}+(\mathrm{H}) \rightarrow \mathrm{CH}_{2} \mathrm{CO}+(\mathrm{H}) \rightarrow \mathrm{CH}_{3} \mathrm{CO}+(\mathrm{H}) \rightarrow \mathrm{CH}_{3} \mathrm{CHO}+(\mathrm{H}) \rightarrow$ $\mathrm{CH}_{3} \mathrm{CH}_{2} \mathrm{O}+(\mathrm{H}) \rightarrow \mathrm{C}_{2} \mathrm{H}_{5} \mathrm{OH}$.

Layered double hydroxide ( $\mathrm{LDH}$ ) materials have also been applied to produce HA because of unique structural characteristic comprising uniformly distributed $\mathrm{Cu}^{2+}$ and $\mathrm{Fe}^{3+}$ ions, resulting in $\mathrm{FeCu}$-based systems with high metal intermixing. Gao et al. [56] modulated the molar $\mathrm{Cu} / \mathrm{Fe} / \mathrm{Mg}$ ratio $(0.4 / 1 / 3.6$, $1.6 / 1 / 3.7$, and $2.5 / 1 / 3.7$, respectively) to achieve the highest CO conversion $(57 \%)$ and total alcohol selectivity $\left(49 \%, \mathrm{C}_{2+} \mathrm{OH}\right.$ selectivity 67\%). High-angle annular dark-field (HAADF)-STEM-EDS images show the highly uniform distribution of $\mathrm{Fe}$ and $\mathrm{Cu}$, which is claimed to be responsible for the
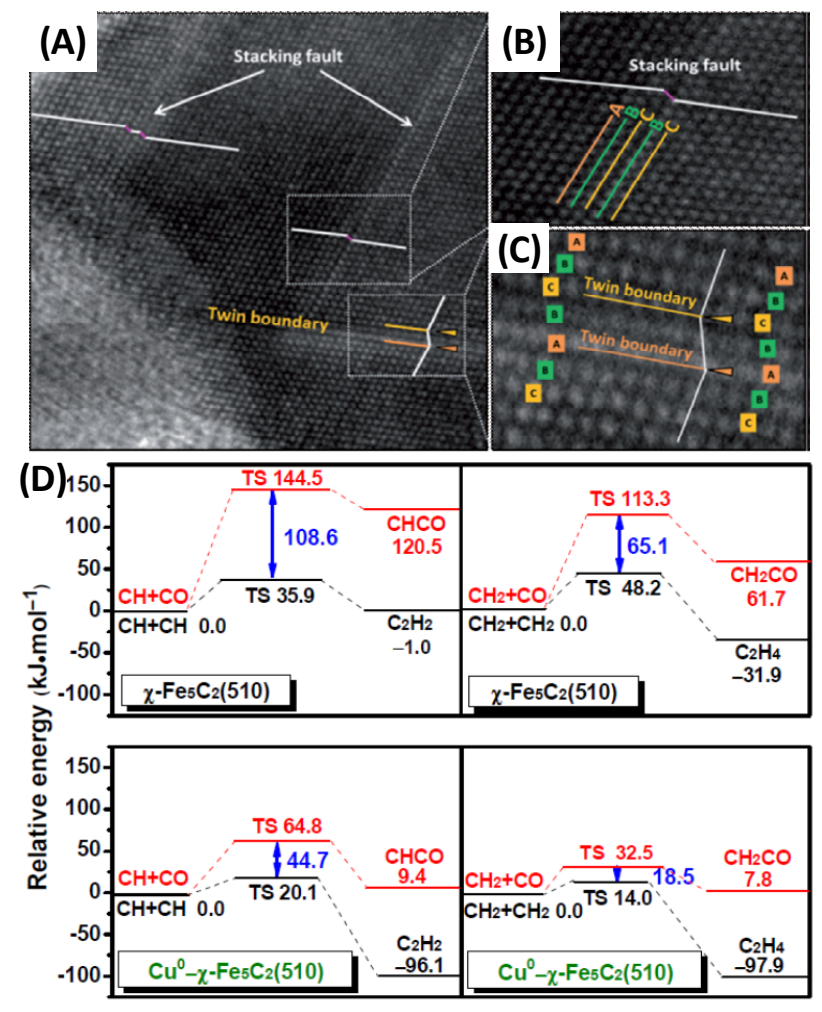

Reaction coordinate

Fig. 8. (A) HRTEM. (B, C) Magnification of (A) shows the stacking fault and twin boundary. Reproduced with permission from Ref. [54]. Copyright 2014, Wiley. (D) The potential energy profiles of $\mathrm{CH}_{x}+\mathrm{CH}_{x}(x=1$, 2) coupling and $\mathrm{CO}$ insertion into $\mathrm{CH}_{x}(x=1,2)$ on $\chi-\mathrm{Fe}_{5} \mathrm{C}_{2}(510)$ and $\mathrm{Cu}^{0}-\chi-\mathrm{Fe}_{5} \mathrm{C}_{2}(510)$, respectively. Reproduced with permission from Ref. [55]. Copyright 2017, American Chemical Society.

high total alcohol selectivity. $\mathrm{H}_{2}$-temperature programmed reduction (TPR) characterization of the catalyst and reference pure-phase materials indicate that the fine distribution of $\mathrm{Fe}$ and $\mathrm{Cu}$ in the former improved their reducibility.

The choice of carrier and promoter also play a vital role in the synthesis of higher alcohols. Ding et al. [57,58] recently used commercially available silica gel (SG) and silica sol (SS) (SG/SS $=19 / 1,4 / 1,3 / 2$, and $1 / 4$ ) to produce a series of bimodal carriers with different pore structures by the incipient-wetness impregnation method. In particular, both the activity $(31 \%-56 \%)$ and $\mathrm{C}_{2+} \mathrm{OH}$ selectivity $(18 \%-45 \%)$ increased with the gradually decreasing bimodal carrier pore sizes (Fig. 9(C)). The results from BET, XRD, and TPR (Fig. 9(A)-(B)) measurements indicate that decreasing the carrier pore sizes leads to the dispersion of active $\mathrm{Cu}$ and $\mathrm{Fe}$ species inside the pore structures, which strengthened the synergistic effect of $\mathrm{Cu}-\mathrm{Fe}$ via the confinement effect of bimodal pore structures, improving the higher alcohol selectivity. After that, the group studied the use of Mn as a promoter [59]. The incorporation of manganese into the $\mathrm{Fe}-\mathrm{Cu}$ based catalysts facilitated the formation of a Fe-Mn-O solid solution and promoted the dispersion of both the iron and copper species through $\mathrm{N}_{2}$ physisorption, XRD, TPR, and temperature-programmed desorption (TPD) measurements. The optimum performance (CO conversion $=26 \%$, alcohols selectivity $=61 \%, \mathrm{C}_{2}+\mathrm{OH}$ selectivity $=$ 

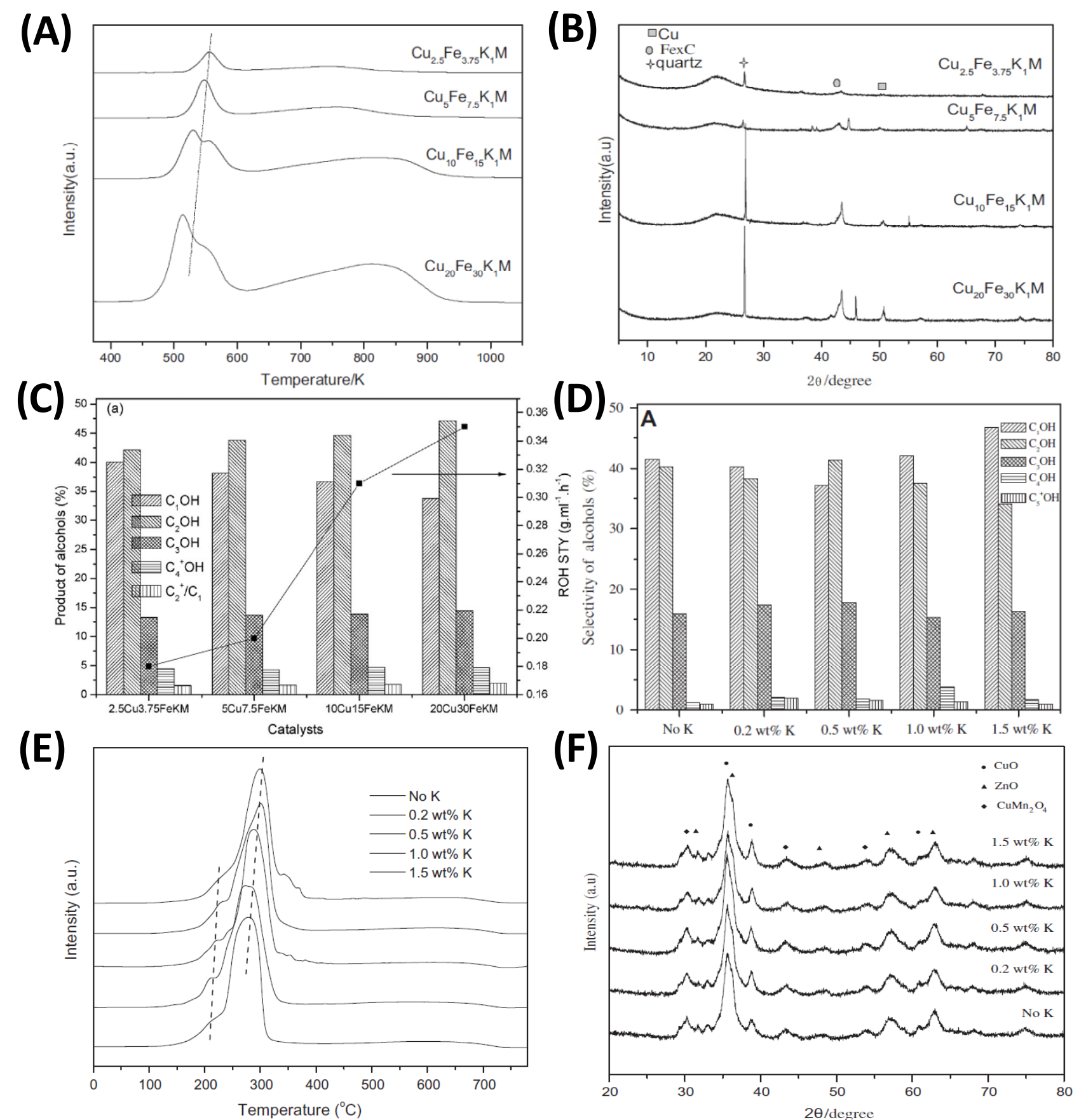

Fig. 9. (A) The $\mathrm{H}_{2}$-TPR profiles of the bimodal catalysts. (B) The XRD patterns of the used catalysts. (C) The product distribution of the bimodal catalysts: higher alcohol product distribution. Reproduced with permission from Ref. [58]. Copyright 2014, Elsevier. (D) The product distribution of the catalysts: higher alcohol product distribution. (E) $\mathrm{H}_{2}$-TPR profiles of the catalysts. (F) XRD patterns of the fresh catalysts. Reproduced with permission from Ref. [60]. Copyright 2015, Elsevier.

$62 \%$ ) is obtained at $270{ }^{\circ} \mathrm{C}$ and $6.0 \mathrm{MPa}$, which may be attributed to the good dispersion of both the iron and copper surface active sites with a higher manganese content. In addition, they investigated the effects of the application of $\mathrm{K}$ to a FeMnCuZn system for HAS [60]. A co-precipitated catalyst of molar $\mathrm{Fe} / \mathrm{Mn} / \mathrm{Cu} / \mathrm{Zn}=0.15 / 1 / 1 / 1$ was impregnated with different amounts of $\mathrm{K}(0.2-1.5 \mathrm{wt} \%)$. Both the CO conversion (27\%) and the $\mathrm{C}_{2}+\mathrm{OH}$ selectivity (63\%) followed a volcano pattern as a function of $\mathrm{K}$ loading, having a maximum at $0.5 \mathrm{wt} \% \mathrm{~K}$
(Fig. 9(D)). Based on the BET, XPS, XRD, and $\mathrm{H}_{2}$-TPD/TPR characterization results (Fig. $9(\mathrm{E})-(\mathrm{F})$ ), the incorporation of $\mathrm{K}$ in the $\mathrm{Cu}-\mathrm{Fe}$ based catalyst decreased the surface area of the particles, and the increase in $\mathrm{K}$ concentration weakened the $\mathrm{H}_{2}$ chemisorption and restrained the reduction of both the $\mathrm{Cu}$ and Fe species, which explain why excess $\mathrm{K}$ resulted in the reduction in catalyst activity, that is, the loss in surface area and the blocking of the active sites. Lu et al. [61] investigated the effect of support pretreatment with ammonia on the performance of 
a $\mathrm{Cu}-\mathrm{Fe} / \mathrm{SiO}_{2}$ conventional catalyst. The $\mathrm{CO}$ conversion and the space-time yield of alcohols of the $\mathrm{Cu}-\mathrm{Fe} / \mathrm{SiO}_{2}$ catalyst increased after pretreatment with ammonia, from $14.8 \%$ and $89.0 \mathrm{~g} \mathrm{~kg}^{-1} \mathrm{~h}^{-1}$ to $17.4 \%$ and $107.0 \mathrm{~g} \mathrm{~kg}^{-1} \mathrm{~h}^{-1}$, respectively. As shown by XRD, $\mathrm{N}_{2}$ adsorption-desorption, $\mathrm{H}_{2}$-TPR, and $\mathrm{N}_{2} \mathrm{O}$ chemisorption measurements, the pretreatment of $\mathrm{SiO}_{2}$ with ammonia resulted in the formation of more active sites of $\mathrm{Cu}$ and higher dispersion of Fe species on the catalyst surface and enhanced the synergistic effect between the copper and iron species.

Attapulgite (ATP) was employed as a carrier by Guo et al. [62] in their assessment of CuFeCo-based catalysts featuring different molar $\mathrm{Cu} / \mathrm{Fe}$ ratios $(9.4 / 0.6,7 / 3,5.2 / 4.8,3 / 7$, and 0.5/9.5). Based on BET and TEM measurements, the enrichment of Fe facilitated the dispersion of oxide particles and the separation of the $\mathrm{Cu}-\mathrm{Fe}$ alloy phase, and the catalyst particle size reduced from 2-4.5 to 1-2 $\mathrm{nm}$. For $\mathrm{Cu}_{9.4} \mathrm{Fe}_{0.6}, \mathrm{Cu}_{7} \mathrm{Fe}_{3}$, and $\mathrm{Cu}_{5.2} \mathrm{Fe}_{4.8}$ samples, HRTEM and XRD observation showed the coexistence of $\mathrm{CuO}$ and $\mathrm{CuFe}_{2} \mathrm{O}_{4}$ phases in close vicinity. Excess $\mathrm{Fe}$, however, led to the formation of $\mathrm{Fe}_{2} \mathrm{O}_{3}$, which can generate segregated $\mathrm{FeC}_{x}$ and $\mathrm{Fe}_{3} \mathrm{O}_{4}$ phases during the reaction. Accordingly, the coverage of $\mathrm{CuFe}_{2} \mathrm{O}_{4}$ by $\mathrm{Fe}_{2} \mathrm{O}_{3}$ was suggested to be the cause of inhibition of alcohol formation.

\subsection{Cobalt catalysts}

Research into Co-based materials for this reaction dates back to 1978 when the first patents were published. Similar to Fe-based catalysts, pure Co catalysts hardly produce higher alcohols, and a second active component or promoter is needed to provide $\mathrm{CO}$ insertion sites for higher alcohols synthesis.

Xiang et al. [63] have focused on CoCu-based catalysts for several years and determined some rules for performance modulation. They prepared CoCuMn core-shell NPs with equal molar amounts of the metals and a tailored shell composition using oxalate-based co-precipitation. The NPs were characterized by atom probe microscopy to reveal the intragranular structure of the nanoparticles, which indicated a diameter of 18 $\mathrm{nm}$ and the presence of a Co core and Cu-rich CoCuMn shell through 3D tomographic reconstruction (Fig. 10(A)-(B)). Using stoichiometric $\mathrm{CO} / \mathrm{H}_{2}$ feeds, the selectivity to 1 -alcohols or combined 1-alcohols/1-alkenes are usually higher than $60 \%$ and occasionally up to $95 \%$ with very low $\mathrm{CO}_{2}$ selectivity (below $10 \%$ ). Subsequently, they showed the impact of the activation atmosphere $\left(\mathrm{CO}, \mathrm{H}_{2}\right.$, syngas, and $\left.\mathrm{Ar}\right)$ on the catalyst structure and, thus, on the catalytic performance of $\mathrm{CoCu}$-catalyst [64]. The CO-activated catalyst shows significantly higher catalytic activity, but the alcohol selectivity is lower than those of $\mathrm{H}_{2}$ - or syngas-activated ones. An "onion-like" graphitic carbon shell was observed via TEM for the CO-activated $\mathrm{Co}_{2} \mathrm{Cu}_{1}$ catalyst in accordance with the temperature programmed decomposition (TPDec) profiles and XPS results, which probably originated from the Boudouard reaction $\left(2 \mathrm{CO} \rightarrow \mathrm{C}+\mathrm{CO}_{2}\right)$. The surface segregation of $\mathrm{Co}$ in a $\mathrm{CO}$ atmosphere results from syngas and $\mathrm{CO}$ activation, which results in higher than nominal $\mathrm{Co} / \mathrm{Cu}$ surface ratios. The same synthesis method used for CoCuMn was applied to prepare another ternary system (Co-
CuNb) but following a two-step strategy [65]. Ammonium niobate (V) oxalate was first precipitated with oxalic acid in acetone and then $\mathrm{Co}$ and $\mathrm{Cu}$ nitrates were added to the mixture. The selectivity to primary alcohols with an optimized C2-C5 slate usually exceeded $50 \mathrm{wt} \%$. As indicated by HRTEM, the bimodal nanosized particle distribution contained $\mathrm{Co}-\mathrm{Cu}$ particles with sizes ranging from 25 to $40 \mathrm{~nm}$ and smaller $\mathrm{Nb}$ oxides particles between 4 and $8 \mathrm{~nm}$ as a structural dispersant and promoter. Recently, they found that the K-promoted CoMn catalysts without $\mathrm{Cu}$ also produced alcohols [11]. The selectivity of long-chain aldehydes, alcohols, olefins, and paraffin could be tuned by changing the $\mathrm{H}_{2} / \mathrm{CO}$ pressure ratio. The sum selectivity of aldehydes and alcohols is usually $50 \mathrm{wt} \%$, of which up to $97 \%$ can be aldehydes. While the product slate contains $60 \%$ $n$-aldehydes at $p \mathrm{H}_{2} / p \mathrm{CO}=0.5$, a $65 / 35 \%$ slate of paraffins/alcohols is obtained at $p \mathrm{H}_{2} / p \mathrm{CO}=9$ (Fig. 10(E)). The synergistic interaction between the $\mathrm{Mn}_{5} \mathrm{O}_{8}$ oxide and bulk $\mathrm{Co}_{2} \mathrm{C}$ phase promoted by the presence of potassium was responsible for the unique product distribution (Fig. 10(C)-(D)).

One of the most relevant studies was recently reported by Prieto et al. [66], who combined DFT simulations and microkinetic modeling with experimental results over $\mathrm{CoCu} / \mathrm{MoO}_{x}$ showing that mixed CoCu NPs slightly enriched in Co on the surface are responsible for selective HAS processes. The calculations predicted the selectivities for $\mathrm{CH}_{4}$, methanol, and ethanol on surfaces possessing different proportions of $\mathrm{Co}$ and $\mathrm{Cu}$. The authors then prepared materials with different molar $\mathrm{Cu} /(\mathrm{Cu}+\mathrm{Co})$ ratios and summarized the evolution of the crystalline metal phases in the CuCo alloy by XRD. In addition, the extent of reduction of the surface Co was determined by XPS as a function of the catalyst composition. The highest time yield of

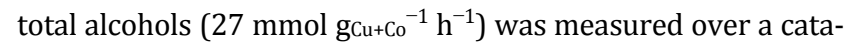
lyst with $\mathrm{Cu} /(\mathrm{Cu}+\mathrm{Co})=0.3$.

Wang et al. [67] prepared $\mathrm{Co} / \mathrm{Al}_{2} \mathrm{O}_{3}, \mathrm{Cu} / \mathrm{Al}_{2} \mathrm{O}_{3}$, and Co$\mathrm{Cu} / \mathrm{Al}_{2} \mathrm{O}_{3}$ materials with different mass $\mathrm{Co} / \mathrm{Cu}$ ratios by the co-incipient wetness method. Based on the XRD and EXAFS results, they claimed that the strong interaction between Co and $\mathrm{Cu}$ oxide particles led to the formation of a $\mathrm{CuCo}_{2} \mathrm{O}_{4}$ mixed spinel structure. The generation of bimetallic $\mathrm{CoCu}$ particles in the reduced sample was confirmed by in situ magnetic measurements and resulted in superior alcohol selectivity (23\%). Su et al. [68] conducted a comparative study of $\mathrm{Co} / \mathrm{SiO}_{2}$ and $\mathrm{Co}-$ $\mathrm{Cu} / \mathrm{SiO}_{2}$ to elucidate the role of $\mathrm{Cu}$. Using XRD, Raman spectroscopy, and X-ray absorption spectroscopy (XAS), they demonstrated the presence of the $\mathrm{CuCo}_{2} \mathrm{O}_{4}$ spinel. Additionally, based on a kinetic study, they suggested that the roles of $\mathrm{Cu}$ were to reduce the formation of $\mathrm{CH}_{x}$ species by weakening the CO/HCO dissociation and to control the surface Co ensemble size inhibiting $\mathrm{CH}_{x}$ insertion.

An in situ growth method was used by Gao et al. [69] to fabricate $\mathrm{Al}_{2} \mathrm{O}_{3}$-supported NPs having a $\mathrm{Cu}$-rich core and a Co$\mathrm{Cu}$-alloy shell. $\mathrm{Cu}$ and $\mathrm{Co}$ nitrates $(\mathrm{Cu} / \mathrm{Co}=0.2-5)$ were dissolved in water and the $\mathrm{pH}$ was adjusted to 6.5 using ammonia. Then, the mixture was heated at $80{ }^{\circ} \mathrm{C}$ for $48 \mathrm{~h}$ in an autoclave containing an $\mathrm{Al}$ foil onto which the CoCuAl-LDH precursor was formed. The precursor was activated by calcination in air followed by reduction. TEM and HAADF-STEM-EDS measure- 



Fig. 10. (A) Atom probe microscopy results from the CoCuMn catalyst nanoparticles, where Co atoms are depicted as blue spheres, $\mathrm{Cu}$ atoms as orange spheres, $\mathrm{Mn}$ atoms as green spheres, and $\mathrm{O}$ as white spheres. (B) A 3D sectional view of the element distribution. Reproduced with permission from Ref. [63]. Copyright 2013, American Chemical Society. (C) HRTEM image and (inset) its Fourier transform. (D) XRD patterns of $\mathrm{Co}_{4} \mathrm{Mn}_{1} \mathrm{~K}_{0.1} \mathrm{cata}$ lyst: both before and after $\mathrm{CO}$ hydrogenation. (E) Product selectivity without $\mathrm{CO}_{2}, \mathrm{CO}$ conversion, and $\mathrm{CO}_{2}$ selectivity, Anderson-Schultz-Flory (ASF) behavior for total $\mathrm{C}_{n}$ for the same catalyst showing a chain-lengthening probability independent of the $\mathrm{H}_{2} / \mathrm{CO}$ pressure ratio. Reproduced with permission from Ref. [11]. Copyright 2017, Nature.

ments confirmed the core-shell structure of the NPs and indicated an average diameter of $15 \mathrm{~nm}$. The best catalyst featured a 0.5 value of $\mathrm{Cu} / \mathrm{Co}$ ratio and displayed a $\mathrm{CO}$ conversion of $22 \%$ and a total primary alcohol selectivity of $51 \mathrm{wt} \%$, being superior to the reference powdered $\mathrm{CoCu} / \mathrm{Al}_{2} \mathrm{O}_{3}$ catalyst $(13 \%$ and 39 wt $\%$, respectively). The high HA selectivity was attributed to the presence of a CoCu-alloy at the shell of the NPs, which enabled intimate interaction between the metals with high stability over $48 \mathrm{~h}$.

Ning et al. [70] synthesized a uniformly dispersed CoGa cat- 
alyst derived from CoZnGaAl-LDHs after direct reduction. As indicated by HRTEM and HAADF element mapping (Fig. 11(A)-(B)) and line scans, the CoGa particles were trapped in the oxide support, which is a unique structure that is not only highly active and selective but also distinctively stable compared to other control samples. A 43.5\% CO conversion with an alcohol selectivity of $59 \%$ was achieved, and, in the alcohol products, the fraction of ethanol and higher alcohols reached 93\% (Fig. 11(C)-(D)). More significantly, the trapped CoGa showed no visible changes in particle dispersion and homogeneous CoGa distribution in the reaction, resulting in stable catalytic performance. In the next year, An et al. [71] continued to reveal the promoting effect of Ga on the Co sites. Through HRTEM and EXAFS measurements, the $\mathrm{Co}_{1} \mathrm{Ga} 0.6-\mathrm{ZnAl}-\mathrm{LDO} / \gamma-\mathrm{Al}_{2} \mathrm{O}_{3}$ was found to have a uniform dis- persion of CoGa particles and pseudo-homogeneous distribution of Co and Ga. The Ga atoms next to Co atoms not only contributed to isolating the Co centers but also donating electrons to neighboring Co sites, as shown by XPS measurements, which promoted dissociative $\mathrm{CO}$ adsorption and enhanced carbon chain growth. The isolated Co sites were responsible for linearly nondissociative CO adsorption, as shown by in situ FTIR measurements, boosting the $\mathrm{CO}$ insertion step to afford alcohol products (Fig. 11(E)-(F)). The match of $\mathrm{CO}$ insertion and C-C coupling gave rise to both enhanced activity in the syngas conversion and impressive selectivity to ethanol and higher alcohols.

Wang et al. [72] promoted Co-Cu catalysts with $\mathrm{Zr}$, $\mathrm{Al}$, or La. Under differential conditions, $\mathrm{CoCuLa}_{2} \mathrm{O}_{3}$ displayed the highest selectivity towards total alcohols (35\%) and the lowest selec-
(A)

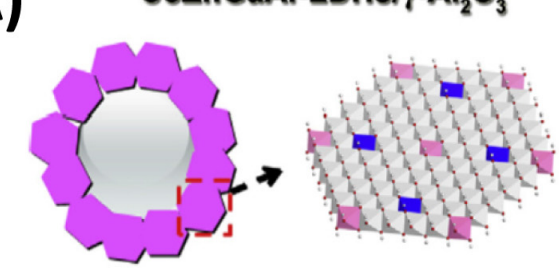

\section{CoGa-ZnAl-LDO/y-Al $\mathrm{O}_{3}$}
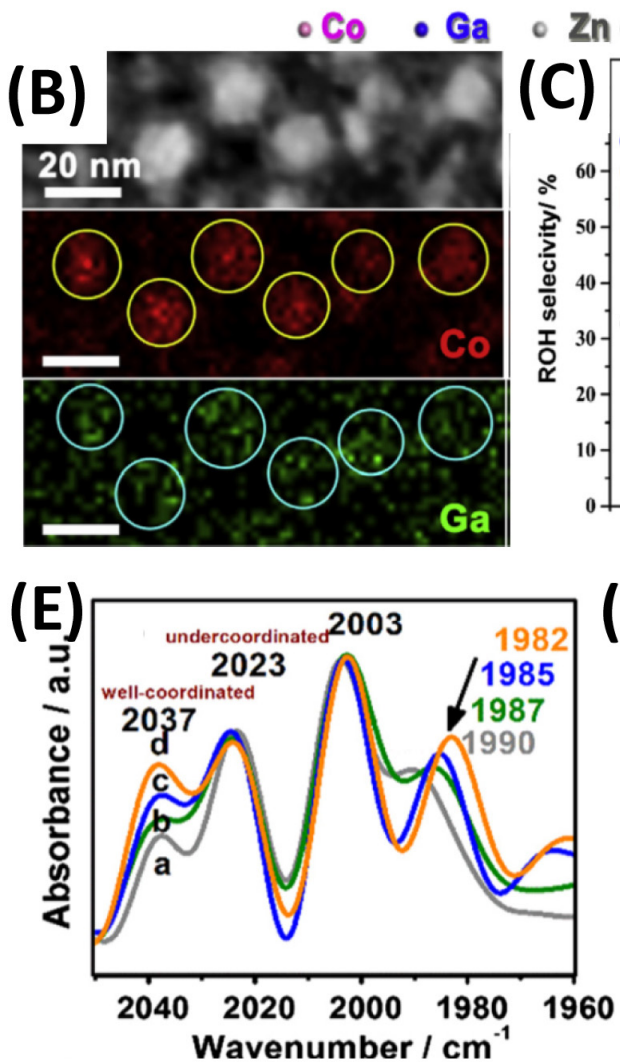
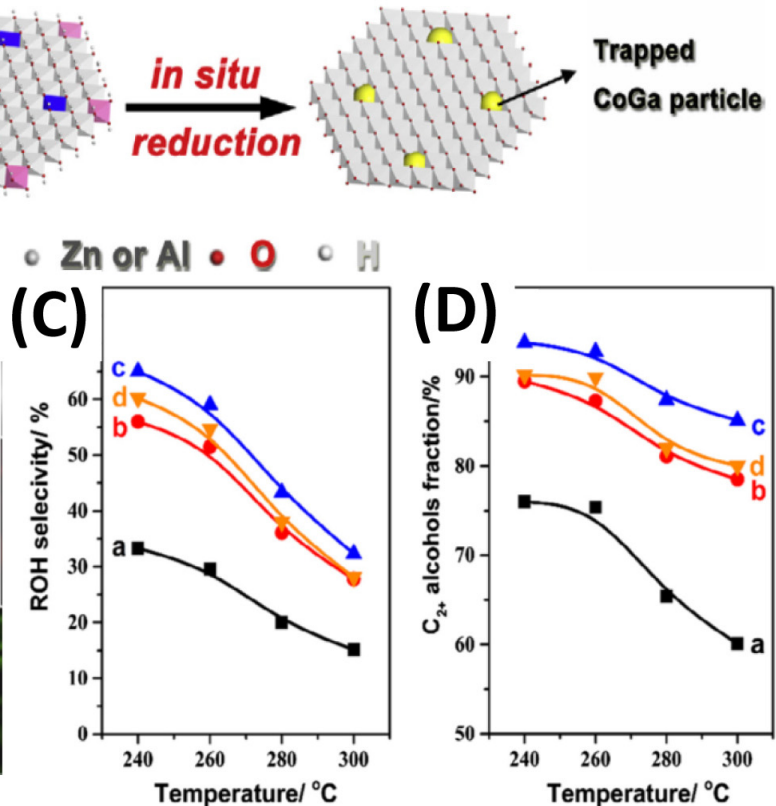

F)

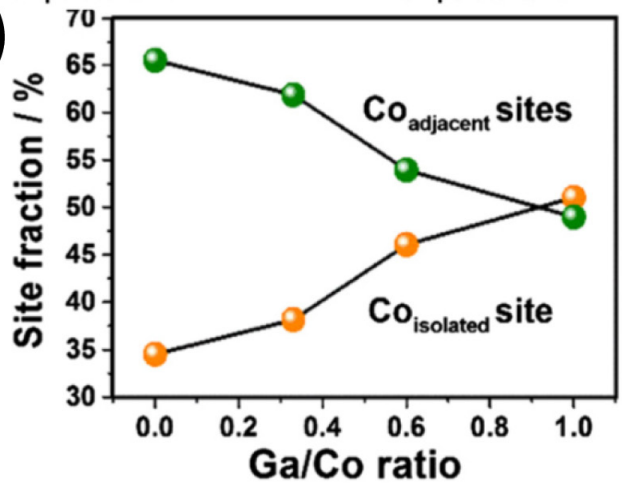

Fig. 11. (A) Schematic illustration for the preparation of uniformly dispersed and trapped CoGa particles from LDH precursors. (B) HAADF images with $\mathrm{Co}$ (red) and Ga (green) element mapping for CoGa-ZnAl-LDO/ $\gamma-\mathrm{Al}_{2} \mathrm{O}_{3}$. Reproduced with permission from Ref. [70]. Copyright 2016, Elsevier. (C) Alcohol selectivity and (D) $\mathrm{C}_{2+}$ alcohol fraction as functions of reaction temperature, and (E) FT-IR spectra of CO absorbed at $30{ }^{\circ} \mathrm{C}$ on (a) $\mathrm{Co}-\mathrm{ZnAl}-\mathrm{LDO} / \gamma-\mathrm{Al}_{2} \mathrm{O}_{3}$ (black squares), (b) $\mathrm{Co} 1 \mathrm{Ga} 0.3-\mathrm{ZnAl}-\mathrm{LDO} / \gamma-\mathrm{Al}_{2} \mathrm{O}_{3}$ (red circles), (c) $\mathrm{Co} 1 \mathrm{Ga} 0.6-\mathrm{ZnAl}-\mathrm{LDO} / \gamma-\mathrm{Al}_{2} \mathrm{O}_{3}$ (blue triangles), and (d) Co1Ga1.0-ZnAl-LDO $/ \gamma-\mathrm{Al}_{2} \mathrm{O}_{3}$ (orange inverted triangles). (F) Site fractions (\%) of active single and adjacent double Co sites. Reproduced with permission from Ref. [71]. Copyright 2017, Elsevier. 
tivity to hydrocarbons (14\%). The authors suggested that the surface basicity provided by $\mathrm{La}_{2} \mathrm{O}_{3}$ favored alcohol formation. $\mathrm{Co}_{2} \mathrm{C}$ is also considered to be an effective phase for $\mathrm{CO}$ insertion for the production of higher alcohols. Pei et al. [52] used up to $3.8 \mathrm{wt} \% \mathrm{Al}_{2} \mathrm{O}_{3}$ as a promoter for Co (15 wt\%)/AC. Both the CO conversion and the total alcohols selectivity reached maximal values at a loading of $0.2 \mathrm{wt} \%(69 \%$ and $28 \%$, respectively, $96 \%$ HA in the alcohols). The authors claimed that the main effect of $\mathrm{Al}_{2} \mathrm{O}_{3}$ was to induce the formation of $\mathrm{Co}_{2} \mathrm{C}$ and change the ratio between adsorbed $\mathrm{H}_{2}$ and CO. Later, using DFT calculations they found that the formation of the stable cobalt carbide and the $\mathrm{Co}_{-} \mathrm{Co}_{2} \mathrm{C}$ interface were essential for the observed reactivity [73]. The calculations show that $\mathrm{Co}_{2} \mathrm{C}$ is highly efficient for $\mathrm{CO}$ nondissociative adsorption, whereas the Co metal is highly active for CO dissociative adsorption and subsequent carbon-chain growth. The interface between the cobalt metal and its carbide phase could be used for higher alcohol synthesis in syngas conversion.

\section{Summary and prospects}

The recent progress in the preparation, characterization, and mechanism of $\mathrm{Fe} / \mathrm{Co}$-based catalysts for syngas conversion reactions to oil, olefin/aromatic, and higher alcohols has been summarized in this review. Because of their comparable catalytic performance to noble metals catalysts, a great number of $\mathrm{Fe} / \mathrm{Co}$ catalysts with high activity have been reported. However, several key issues, including harsh reaction conditions, low stability, and unsatisfactory selectivity, remain unresolved with respect to the demands of industrial applications. To develop advanced catalysts with high performance rationally, a deepening of the basic understanding of catalyst science in this area is imperative. The following problems have been identified: (1) although $\mathrm{Fe} / \mathrm{Co}$-based catalysts show good catalytic activity in these reactions, the specific selectivity and product distribution have not been well modulated; (2) it is rather difficult to maintain the structure of active sites as a result of aggregation/sintering, phase transformation, and carbon deposition under the harsh reaction conditions (e.g., high temperature and high pressure); and (3) because of the complexity of reaction system normally involving a number of elementary steps, the reaction mechanism must be urgently identified.

To solve the problems mentioned above, the following proposed strategies are feasible. First, further catalyst design and synthesis exploration are necessary, for example, through the development of new synthetic methods and activation conditions. Especially for higher alcohol synthesis, determining how to tune the synergistic effect between $\mathrm{CO}$ insertion site and $\mathrm{C}-\mathrm{C}$ coupling site to enhance the selectivity is the key challenge that requires both a high homogeneous dispersion and a balanced rate of the two active sites. Therefore, polymetallic catalysts prepared by in situ growth methods, such as LDHs and montmorillonite, via the fine control of the reduction conditions could give rise to a precise tuning of the synergistic effect between individual active centers. This may lead to new developments in syngas conversion. Secondly, utilizing the strategy of the strong metal-support interaction (SMSI) for promoting specific product selectivity provides supplementary or even an indispensable approach to experimental studies. For the FTO process, the key issue is that the generated olefin must be immediately desorbed to prevent continuous hydrogenation to paraffin. Through the modulation of reducible oxides as supports, like $\mathrm{TiO}_{x}$ and $\mathrm{MnO}_{x}$, the appropriate surface electronic and geometric structure at the interface, or even new active phases such as $\mathrm{Co}_{2} \mathrm{C}$, could be achieved; these not only promote the activity but also weaken the $\mathrm{C}-\mathrm{C}$ coupling for increased selectivity for $\mathrm{C}_{2}-\mathrm{C}_{4}$ olefins. Finally, although calculations have been recognized as a powerful tool to simulate the reaction mechanism on a defined catalytic active site, the results are still far from reality. This is because the real crystal surfaces are more complicated than the ideal crystal surfaces used in calculations. Under reaction conditions, the actual catalyst surface has an abundance of step/corner sites and defects resulting from preparation technology and reconstitution through the adsorption of reactants and intermediates, and the simulation of these factors is challenging. Thus, in situ experimental studies are urgently needed to obtain detailed structural information on active sites and reaction mechanisms under practical conditions. For example, in situ XAS could not only provide the reversible valence state change to show the electron transfer between catalyst and adsorbate directly but also reflect the variation of coordination number and bonding situation resulting from the reconstruction on the bulk/surface of the catalysts; in situ IR can be used to monitor the structure change of reactant molecules directly and observe the intermediates of the main reaction path, which could also be identified in combination with mass spectrometry. Therefore, based on the results of in situ XAS and IR, the establishment of an intimate correlation can be employed to understand the active site-dependent reaction mechanism fully.

Moreover, novel reactive modes and strategies might trigger a new focus of research. Changing heterogeneous reactions to homogeneous reactions could not only optimize reaction conditions (reducing the reaction temperature and pressure), but also control the product selectivity and promote product separation through the modulation of solvent. In the case of FTS in the aqueous phase, the temperature can be reduced to $160{ }^{\circ} \mathrm{C}$ for improved FTS performance. Because of the polarity of higher alcohols, the desorption of the product can be promoted by using water as the solvent with new catalyst systems. Meanwhile, taking into account the tandem reaction applied in industrial production, the strategy of reaction coupling has been developed to promote specific product selectivities and space-time yields. In the FTO process, either methanol or ketene (the intermediates of the first reaction) should be able to react on the latter catalyst such as HZSM-5 molecular sieves. From the viewpoint of environmental protection and Mars exploration, the substitution of $\mathrm{CO}$ by $\mathrm{CO}_{2}$ for analogous FTS could become a fast-growing field with wide-ranging research significance and prospective applications for mitigating the greenhouse effect. Owing to the more facile adsorption of $\mathrm{CO}_{2}$ on the catalyst surface compared to $\mathrm{CO}$, the use of $\mathrm{CO}_{2}$ is appropriate to produce methanol and higher alcohols, although methanation is still the main problem. In addition, the extreme 


\section{Graphical Abstract}

Chin. J. Catal., 2018, 39: 1329-1346 doi: 10.1016/S1872-2067(18)63100-6

\section{New development in Fe/Co catalysts: Structure modulation and performance optimization for syngas conversion}

Yinwen Li, Xin Zhang*, Min Wei*

Beijing University of Chemical Technology

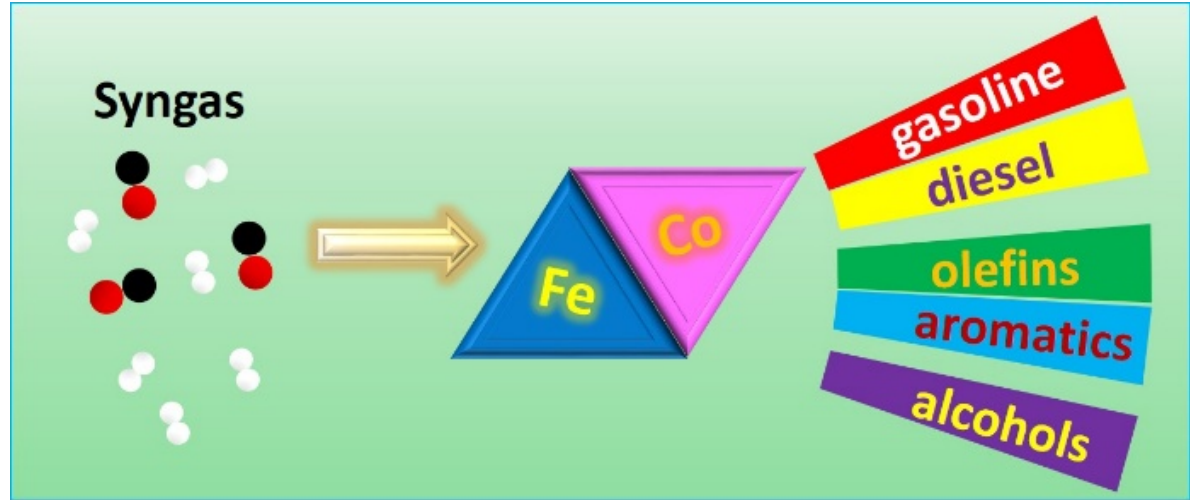

This review comprehensively overviews syngas conversion based on Fe/Co catalysts in three main reactions, highlights the advances recently made and the challenges that remain open, and will stimulate upcoming research activities.

inertness of $\mathrm{CO}_{2}$ and the high kinetic barriers for the formation of $\mathrm{C}-\mathrm{C}$ bonds result in a great challenge to directly synthesize $\mathrm{C}_{2+}$ products from $\mathrm{CO}_{2}$, and this area deserves an in-depth investigation on new catalysts and reaction pathway.

\section{References}

[1] E. de Smit, F. Cinquini, A. M. Beale, O. V. Safonova, W. van Beek, P. Sautet, B. M. Weckhuysen, J. Am. Chem. Soc., 2010, 132, 14928-14941.

[2] C. Yang, H. B. Zhao, Y. L. Hou, D. Ma, J. Am. Chem. Soc., 2012, 134, 15814-15821.

[3] V. Navarro, M. A. van Spronsen, J. W. M. Frenken, Nat. Chem., 2016, 8, 929-934.

[4] P. Munnik, N. A. Krans, P. E. de Jongh, K. P. de Jong, ACS Catal., 2014, 4, 3219-3226.

[5] X. Q. Zhang, R. A. van Santen, E. J. M. Hensen, ACS Catal., 2015, 5, 596-601.

[6] J. H. den Otter, K. P. de Jong, Top. Catal., 2013, 57, 445-450.

[7] H. M. Torres Galvis, J. H. Bitter, T. Davidian, M. Ruitenbeek, A. I. Dugulan, K. P. de Jong, J. Am. Chem. Soc., 2012, 134, 16207-16215.

[8] L. S. Zhong, F. Yu, Y. L. An, Y. H. Zhao, Y. H. Sun, Z. J. Li, T. J. Lin, Y. J. Lin, X. Z. Qi, Y. Y. Dai, L. Gu, J. S. Hu, S. F. Jin, Q. Shen, H. Wang, Nature, 2016, 538, 84-87.

[9] H. M. Torres Galvis, J. H. Bitter, C. B. Khare, M. Ruitenbeek, A. I. Dugulan, K. P. de Jong, Science, 2012, 335, 835-838.

[10] A. Kiennemann, A. Barama, S. Boujana, M. M. Bettahar, Appl. Catal. A, 1993, 99, 175-194.

[11] Y. Z. Xiang, N. Kruse, Nat. Commun., 2016, 7, 13058-13064.

[12] J. P. Hindermann, A. Razzaghi, R. Breault, R. Kieffer, A. Kiennemann, React. Kinet. Catal. Lett., 1984, 26, 221-226.

[13] T. O. Eschemann, J. H. Bitter, K. P. de Jong, Catal. Today, 2014, 228, 89-95.

[14] Y. Cheng, J. Lin, K. Xu, H. Wang, X. Y. Yao, Y. Pei, S. R. Yan, M. H. Qiao, B. N. Zong, ACS Catal., 2015, 6, 389-399.
[15] P. Zhai, C. Xu, R. Gao, X. Liu, M. Z. Li, W. Z. Li, X. P. Fu, C. J. Jia, J. L. Xie, M. W. Zhao, X. P. Wang, Y. W. Li, Q. W. Zhang, X. D. Wen, D. Ma, Angew. Chem. Int. Ed., 2016, 55, 9902-9907.

[16] D. H. Chun, J. C. Park, S. Y. Hong, J. T. Lim, C. S. Kim, H. T. Lee, J. I. Yang, S. J. Hong, H. Jung, J. Catal., 2014, 317, 135-143.

[17] T. M. Eggenhuisen, P. Munnik, H. Talsma, P. E. de Jongh, K. P. de Jong, J. Catal., 2013, 297, 306-313.

[18] K. Xiao, Z. H. Bao, X. Z. Qi, X. X. Wang, L. S. Zhong, M. G. Lin, K. P. Fang, Y. H. Sun, Catal. Commun., 2013, 40, 154-157.

[19] H. Wang, W. Zhou, J. X. Liu, R. Si, G. Sun, M. Q. Zhong, H. Y. Su, H. B. Zhao, J. A. Rodriguez, S. J. Pennycook, J. C. Idrobo, W. X. Li, Y. Kou, D. Ma, J. Am. Chem. Soc., 2013, 135, 4149-4158.

[20] X. B. Peng, K. Cheng, J. C. Kang, B. Gu, X. Yu, Q. H. Zhang, Y. Wang, Angew. Chem. Int. Ed., 2015, 54, 4553-4556.

[21] X. Liu, C. H. Zhang, Y. W. Li, J. W. Niemantsverdriet, J. B. Wagner, T. W. Hansen, ACS Catal., 2017, 7, 4867-4875.

[22] C. Yang, B. Zhao, R. Gao, S. Y. Yao, P. Zhai, S. W. Li, J. Yu, Y. L. Hou, D. Ma, ACS Catal., 2017, 7, 5661-5667.

[23] J. H. den Otter, S. R. Nijveld, K. P. de Jong, ACS Catal., 2016, 6 , 1616-1623.

[24] P. Munnik, P. E. de Jongh, K. P. de Jong, J. Am. Chem. Soc., 2014, 136, 7333-7340.

[25] J. H. den Otter, H. Yoshida, C. Ledesma, D. Chen, K. P. de Jong, J. Catal., 2016, 340, 270-275.

[26] T. O. Eschemann, J. Oenema, K. P. de Jong, Catal. Today, 2016, 261, 60-66.

[27] T. O. Eschemann, W. S. Lamme, R. L. Manchester, T. E. Parmentier, A. Cognigni, M. Rønning, K. P. de Jong, J. Catal., 2015, 328, 130-138.

[28] W. Chen, B. Zijlstra, I. A. W. Filot, R. Pestman, E. J. M. Hensen, ChemCatChem, 2018, 10, 136-140.

[29] L. Joos, I. A. W. Filot, S. Cottenier, E. J. M. Hensen, M. Waroquier, V. Van Speybroeck, R. A. van Santen, J. Phys. Chem. C, 2014, 118, 5317-5327.

[30] T. H. Pham, Y. Y. Qi, J. Yang, X. Z. Duan, G. Qian, X. G. Zhou, D. Chen, 
W. K. Yuan, ACS Catal., 2015, 5, 2203-2208.

[31] H. M. Torres Galvis, A. C. J. Koeken, J. H. Bitter, T. Davidian, M. Ruitenbeek, A. I. Dugulan, K. P. de Jong, Catal. Today, 2013, 215, 95-102.

[32] M. Oschatz, W. S. Lamme, J. X. Xie, A. I. Dugulan, K. P. de Jong, ChemCatChem, 2016, 8, 2846-2852.

[33] M. Oschatz, J. P. Hofmann, T. W. van Deelen, W. S. Lamme, N. A. Krans, E. J. M. Hensen, K. P. de Jong, ChemCatChem, 2017, 9, 620-628.

[34] M. Oschatz, T. W. van Deelen, J. L. Weber, W. S. Lamme, G. Wang, B. Goderis, O. Verkinderen, A. I. Dugulan, K. P. de Jong, Catal. Sci. Technol., 2016, 6, 8464-8473.

[35] M. Casavola, J. X. Xie, J. D. Meeldijk, N. A. Krans, A. Goryachev, J. P. Hofmann, A. I. Dugulan, K. P. de Jong, ACS Catal., 2017, 7, 5121-5128.

[36] J. X. Xie, H. M. Torres Galvis, A. C. J. Koeken, A. Kirilin, A. I. Dugulan, M. Ruitenbeek, K. P. de Jong, ACS Catal., 2016, 6, 4017-4024.

[37] J. X. Xie, J. Yang, A. I. Dugulan, A. Holmen, D. Chen, K. P. de Jong, M. J. Louwerse, ACS Catal., 2016, 6, 3147-3157.

[38] A. C. J. Koeken, H. M. Torres Galvis, T. Davidian, M. Ruitenbeek, K. P. de Jong, Angew. Chem. Int. Ed., 2012, 51, 7190-7193.

[39] X. Q. Chen, D. H. Deng, X. L. Pan, Y. F. Hu, X. H. Bao, Chem. Commun, 2015, 51, 217-220.

[40] X. Q. Chen, D. H. Deng, X. L. Pan, X. H. Bao, Chin. J. Catal., 2015, 36, 1631-1637.

[41] Y. Liu, J. F. Chen, Y. Zhang, RSC Adv., 2015, 5, 29002-29007.

[42] Y. Liu, Z. H. Li, Y. Zhang, React. Kinet., Mech. Catal., 2016, 119, 457-468.

[43] Z. P. Tian, C. G. Wang, Z. Si, L. L. Ma, L. Chen, Q. Y. Liu, Q. Zhang, H. Y. Huang, Appl. Catal. A, 2017, 541, 50-59.

[44] V. V. Ordomsky, Y. Luo, B. Gu, A. Carvalho, P. A. Chernavskii, K. Cheng, A. Y. Khodakov, ACS Catal., 2017, 7, 6445-6452.

[45] R. Lødeng, O. Lunder, J. E. Lein, P. I. Dahl, I. H. Svenum, Catal. Today, 2018, 299, 47-59.

[46] Y. Y. Qi, C. Ledesma, J. Yang, X. Z. Duan, Y. A. Zhu, A. Holmen, D. Chen, J. Catal., 2017, 349, 110-117.

[47] J. L. Weber, I. Dugulan, P. E. de Jongh, K. P. de Jong, ChemCatChem, 2018, 10, 1107-1112.

[48] Q. G. Yan, Y. W. Lu, C. X. Wan, J. Han, J. Rodriguez, J. J. Yin, F. Yu, Energy Fuels, 2014, 28, 2027-2034.

[49] T. H. Yang, L. K. Cheng, N. Li, D. H. Liu, Ind. Eng. Chem. Res., 2017, 56, 11763-11772.

[50] B. Zhao, P. Zhai, P. F. Wang, J. Q. Li, T. Li, M. Peng, M. Zhao, G. Hu, Y. Yang, Y. W. Li, Q. W. Zhang, W. B. Fan, D. Ma, Chem, 2017, 3, 323-333.

[51] Z. H. Bao, K. Xiao, X. Z. Qi, X. X. Wang, L. S. Zhong, K. G. Fang, M. G. Lin, Y. H. Sun, J. Energy Chem., 2013, 22, 107-113.
[52] Y. P. Pei, Y. J. Ding, H. J. Zhu, J. Zang, X. G. Song, W. D. Dong, T. Wang, Y. Lu, Catal. Lett., 2014, 144, 1433-1442.

[53] K. Xiao, Z. H. Bao, X. Z. Qi, X. X. Wang, L. S. Zhong, K. G. Fang, M. G. Lin, Y. H. Sun, J. Mol. Catal. A, 2013, 378, 319-325.

[54] Y. W. Lu, B. B. Cao, F. Yu, J. Liu, Z. H. Bao, J. S. Gao, ChemCatChem, 2014, 6, 473-478.

[55] Y. W. Lu, R. G. Zhang, B. B. Cao, B. H. Ge, F. F. Tao, J. J. Shan, N. Luan, Z. H. Bao, T. P. Wu, J. W. Pote, B. J. Wang, F. Yu, ACS Catal., 2017, 7, 5500-5512.

[56] W. Gao, Y. F. Zhao, J. M. Liu, Q. W. Huang, S. He, C. M. Li, J. W. Zhao, M. Wei, Catal. Sci. Technol, 2013, 3, 1324-1332.

[57] M. Y. Ding, J. L. Tu, N. Tsubaki, L. G. Chen, T. J. Wang, L. L. Ma, C. G. Wang, in: J. Yan, T. Shamim, S. K. Chou, H. Li Eds., Clean, Efficient and Affordable Energy for a Sustainable Future: The 7th International Conference on Applied Energy (ICAE2015), 2015, 75, 767-772.

[58] M. Y. Ding, J. L. Tu, J. G. Liu, N. Tsubaki, T. J. Wang, L. L. Ma, Catal. Today, 2014, 234, 278-284.

[59] M. Y. Ding, M. H. Qiu, J. G. Liu, Y. P. Li, T. J. Wang, L. L. Ma, C. Z. Wu, Fuel, 2013, 109, 21-27.

[60] M. Y. Ding, J. L. Tu, M. H. Qiu, T. J. Wang, L. L. Ma, Y. P. Li, Appl. Energy, 2015, 138, 584-589.

[61] R. L. Lu, D. S. Mao, J. Yu, Q. S. Guo, J. Ind. Eng. Chem., 2015, 25, 338-343.

[62] H. J. Guo, H. R. Zhang, F. Peng, H. J. Yang, L. Xiong, C. Wang, C. Huang, X. P. Chen, L. L. Ma, Appl. Catal. A, 2015, 503, 51-61.

[63] Y. Z. Xiang, V. Chitry, P. Liddicoat, P. Felfer, J. Cairney, S. Ringer, N. Kruse, J. Am. Chem. Soc., 2013, 135, 7114-7117.

[64] Y. Z. Xiang, R. Barbosa, N. Kruse, ACS Catal., 2014, 4, 2792-2800.

[65] Y. Z. Xiang, R. Barbosa, X. N. Li, N. Kruse, ACS Catal., 2015, 5, 2929-2934.

[66] G. Prieto, S. Beijer, M. L. Smith, M. He, Y. Au, Z. Wang, D. A. Bruce, K. P. de Jong, J. J. Spivey, P.E. de Jongh, Angew. Chem. Int. Ed., 2014, 53, 6397-6401.

[67] J. J. Wang, P. A. Chernavskii, A. Y. Khodakov, Y. Wang, J. Catal., 2012, 286, 51-61.

[68] J. J. Su, Z. P. Zhang, D. L. Fu, D. Liu, X. C. Xu, B. F. Shi, X. Wang, R. Si, Z. Jiang, J. Xu, Y. F. Han, J. Catal., 2016, 336, 94-106.

[69] W. Gao, Y. F. Zhao, H. R. Chen, H. Chen, Y. W. Li, S. He, Y. K. Zhang, M. Wei, D.G. Evans, X. Duan, Green Chem., 2015, 17, 1525-1534.

[70] X. Ning, Z. An, J. He, J. Catal., 2016, 340, 236-247.

[71] Z. An, X. Ning, J. He, J. Catal., 2017, 356, 157-164.

[72] Z. Wang, J. J. Spivey, Appl. Catal. A, 2015, 507, 75-81.

[73] Y. P. Pei, J. X. Liu, Y. H. Zhao, Y. J. Ding, T. Liu, W. D. Dong, H. J. Zhu, H. Y. Su, L. Yan, J. L. Li, W. X. Li, ACS Catal, 2015, 5, 3620-3624.

\title{
$\mathrm{Fe} / \mathrm{Co}$ 催化剂在合成气转化领域的新进展: 结构调控和性能强化
}

\author{
李印文, 张 欣 ${ }^{*}$, 卫 敏 ${ }^{*}$
}

北京化工大学化工资源有效利用国家重点实验室, 北京软物质科学与工程高精尖创新中心, 北京 100029

摘要: $\mathrm{C} 1$ 化学通常是指所有参与反应的分子都只含有一个碳原子, 是煤化学和天然气化学的核心, 其中合成气 $\left(\mathrm{CO}+\mathrm{H}_{2}\right)$ 转 化是其中最重要的工业反应体系. 如今部分国家和地区, 由于能源结构调整和煤炭资源利用, 急需开发更清洁、更高效的 绿色能源. 合成气转化作为煤炭间接液化技术中最重要的一个环节, 根据目标产物的不同已经发展了三个主要的反应体 系: 传统的费托合成制备汽油、柴油和蜡等饱和碳氢化合物, 类费托合成制备以低碳烯烃、芳香化合物为主的不饱和碳氢 化合物, 以及一步转化为高碳醇的含氧化合物.

铁/钴作为两种主要的工业催化剂, 引起了研究者的广泛关注. 不同的产物对于催化体系的要求不同, 即使催化剂的组 
成相同, 仍需对催化剂的结构进行大范围的调变和修饰. 而催化剂结构的改变可以通过载体的选择、助剂的修饰和活化条 件的调控来改变催化剂中活性相的尺寸和分散度、活性位点的电子密度甚至获得新的活性物种. 通过对催化剂进行改性, 我们可以有效的促进反应物的活化、削弱产物的吸附并最终获得目标产物. 与此同时, 反应条件的优化(温度和压力)、反 应介质的转变和不同反应的耦合同样可以极大改变催化性能. 由此可见, 无论是直接对催化剂结构进行修饰还是间接的 改变反应条件都可以有效的提升催化性能.

高效催化剂的设计主要基于结构调控和新反应体系的建立, 本文系统地综述了铁/钴催化剂在合成气转化方面的三个 重要反应和最新研究进展. 第一部分概述了费-托合成反应中关于铁活性物种的辨别与确认、对制备汽油和柴油的性能优 化, 着重介绍了原位技术在该反应中的应用及对催化体系中构效关系的揭示. 第二部分讨论了制备烯烃和芳香化合物等 不饱和碳氢化合物的催化剂结构设计, 总结了产物选择性(尤其是 $\mathrm{C} 2-\mathrm{C} 4$ 烯烃选择性)的调控方法. 第三部分综述了近期报 导的合成气直接转化为高碳醇的催化剂的研究进展, 包括制备方法、载体和助剂对于提升总醇和高碳醇选择性的影响. 最 后, 本文探讨了该领域尚未解决的问题, 主要包括制备烯烃和高碳醇的性能仍距实际工业生产的指标相去甚远、在苛刻的 反应条件下活性位点极难保持稳定的结构、以及反应体系的复杂性对于深入理解反应机理所造成的阻碍, 并从新型催化剂 的制备、金属载体相互作用的调控、原位实验的探究等方面提出了可行的解决方案.

关键词: 合成气转化; $\mathrm{Fe} / \mathrm{Co}$ 催化剂; 结构调控; 性能强化; 产物选择性

收稿日期: 2018-04-10. 接受日期: 2018-05-08. 出版日期: 2018-08-05.

*通讯联系人. 电话/传真: (010)64446598; 电子信箱: zhangxin@mail.buct.edu.cn

\#通讯联系人. 电话: (010)64412131; 传真: (010)64425385; 电子信箱: weimin@mail.buct.edu.cn

基金来源：国家重点研究和发展计划(2017YFA0206804); 国家自然科学基金(91741104); 中央高校基本科研专项基金 (buctylkxj01).

本文的电子版全文由Elsevier出版社在ScienceDirect上出版(http://www.sciencedirect.com/science/journal/18722067). 